\title{
Alianzas y coaliciones en las elecciones de gobernadores en Colombia
}

\author{
Nuevas reglas, fragmentación y \\ coordinación estratégica
}

\section{Alliances and coalitions in elections of governors in Colombia}

\section{New rules, fragmentation and strategic coordination}

\author{
Javier Duque Daza iD \\ Universidad del Valle, Colombia \\ jduqued86@hotmail.com
}

\begin{abstract}
Resumen
Este artículo analiza las coaliciones y las alianzas en las elecciones de gobernadores en Colombia en el periodo 2011 2019. Se explica este tipo de coordinaciones estratégicas a partir de tres factores: las reglas electorales, las caracteristicas de la competencia partidista y la naturaleza de los partidos políticos. El análisis incluye 96 elecciones departamentales (32 departamentos en las elecciones de 2011, 2015 y 2019), recurre a los resultados electorales, a la identificación partidista de las candidaturas, a fuentes hemerográficas, y utiliza el programa Gephi para representar gráficamente las coaliciones y las alianzas ganadoras. El resultado de la investigación se sintetiza en cinco conclusiones: (1) las alianzas y las coaliciones son las estrategias electorales dominantes en este tipo de elecciones; (2) ambas son el resultado de la coordinación entre facciones y partidos altamente personalizados cuya clase política departamental es muy autónoma; (3) la mayoría de alianzas y coaliciones son divergentes, los partidos que son aliados en unos departamentos son rivales y competidores en otros, (5) este predominio de las coaliciones y de las alianzas electorales tienen efectos negativos para la democracia en Colombia.
\end{abstract}

Palabras clave: Coaliciones, elecciones, alianzas, sistema electoral, partidos.

\begin{abstract}
This article analyzes the coalitions and alliances in the elections of governors in Colombia in the period 2011-2019. This type of strategic coordination is explained from three factors: electoral rules, the characteristics of party competition, and the nature of political parties. The analysis includes 96 departamental elections (32 departments in the elections of 2011 , 2015 and 2019), uses electoral results, party identification of candidates, newspaper sources and uses the Gephi program to graphically represent coalitions and alliances winners. The result of the research is synthesized in five conclusions: (1) alliances and coalitions are the dominant electoral strategies in this type of election; (2) both are the result of coordination between highly personalized factions and parties whose departamental political class is highly autonomous; (3) most alliances and coalitions are divergent, the parties that are allies in some departments are rivals and competitors in others, (5) this predominance of coalitions and electoral alliances has negative effects for democracy in Colombia.
\end{abstract}

Keywords: Coalitions, elections, alliances, electoral system, parties.

Articulo: Recibido el 21 de septiembre de 2020 y aprobado el 20 de octubre de 2020

El autor agradece la asistencia de investigación de María Paula Jiménez del Programa de Estudios Políticos y Resolución de Conflictos de la Universidad del Valle. 


\section{Cómo citar este artículo:}

Duque Daza, J. (2020). Alianzas y coaliciones en las elecciones de gobernadores en Colombia Nuevas reglas, fragmentación y coordinación estratégica. Reflexión política 22(46), pp. 8-32. doi: https://doi.org/10.29375/01240781.3990

\section{Introducción}

Desde comienzos de la novena década del siglo XX el sistema político en Colombia presentó grandes transformaciones. Por una parte, tras la reforma de descentralización iniciada en 1980 que instituyó la elección popular de alcaldes (la primera se dio en 1988), con la Constitución Política de 1991 se estableció la elección de gobernadores, y con ello se produjo un importante efecto en la redistribución territorial del poder. Por otra parte, con la nueva carta hubo importantes cambios en el sistema electoral, los cuales continuaron con las reformas políticas de las dos décadas siguientes. En tercer lugar, en el marco de estos cambios, los partidos históricos del país, el Liberal y el Conservador, dejaron de ser los únicos actores políticos, y el bipartidismo prolongado y con alta división interna transitaría hacia un multipartidismo atomizado en 1990, con alto nivel de fragmentación, nuevos partidos estables y mayor pluralismo en las dos décadas siguientes.

Los cambios en las instituciones y en el sistema de partidos se dieron a la vez que se reproducían algunos de los rasgos centrales de los partidos políticos: las divisiones internas en la gran mayoría de agrupaciones políticas, el alto personalismo en los liderazgos, la débil institucionalización organizativa que impedía que las dirigencias centrales tuvieran un control efectivo sobre los políticos de los departamentos, y el predominio de un pragmatismo transaccional con la presencia de políticos de negocios. También continuó -al menos hasta mediados de la década del 2000- la injerencia de organizaciones ilegales en muchos partidos a nivel nacional y regional, ciertas prácticas de fraude electoral y de financiación ilegal de campañas.

En este contexto, un fenómeno político reciente y cada vez más recurrente y de crecientes dimensiones, ha sido la coordinación estratégica en elecciones regionales mediante coaliciones y alianzas electorales. ${ }^{1}$ Sobre estas hay muchas preguntas: ¿Cómo compiten y cómo cooperan los partidos entre sí mediante alianzas y coaliciones en las elecciones regionales? ¿Qué tan frecuentes son las coaliciones y alianzas? ¿Quiénes las conforman? ¿Qué tan exitosas son? ¿Qué efectos tiene su presencia para la democracia en los departamentos?

Las respuestas a estas preguntas han sido hasta ahora parciales, centradas en descripciones y en reportes periodísticos en coyunturas electorales, análisis de la normatividad y algunas comparaciones de los resultados entre dos elecciones o análisis sobre las elecciones de 2015 y 2019. Algunos ensayos reflexionan sobre cómo los partidos ya no son los actores sino las coaliciones, precarias y oportunistas (Hernández, 2013); o describen elecciones específicas y estiman el peso de las coaliciones en el total de las candidaturas (Fernández, 2011; Batle \& Puyana, 2015); o se recurre a la tesis de la crisis de los partidos y al predominio del voto por candidatos y no por partidos (García, 2019; Calderón, 2019; Solano, 2019; Semana, 2019). A su vez, se ha enfatizado en la desarticulación entre los niveles nacional y regional de los partidos (Botero \& Alvira, 2012; Dávila, 2020). Hay otros análisis del desarrollo de la normatividad sobre las coaliciones (Hernández, 2013) y un breve artículo sobre las redes de coaliciones en 2019 y los síntomas de desinstitucionalización del sistema de partidos (Albarracín \& Milanese, 2019). Los más recientes análisis son sobre las elecciones de 2015 y 2019. Un informe institucional sintetiza y compara la normatividad

\footnotetext{
${ }^{1}$ Aunque en otros estudios suelen considerarse sinónimos, en este análisis se diferencian las coaliciones de las alianzas electorales. Ambas son formas de coordinación estratégica que expresan acuerdos entre dos o más actores (políticos, partidos o facciones de partidos) que coordinan sus acciones y eligen a un candidato conjunto para competir en mejores condiciones y con mayores probabilidades de éxito por la agregación de electorados (Ordeshook, 1986; Cox, 1997), pero se diferencian en que las coaliciones son formalizadas mediante procedimientos legales, son acuerdos explícitos y públicos, mientras que las alianzas son informales, no siempre son explícitas ni públicas, y en ocasiones son adhesiones por iniciativa de una de las partes que después son aceptadas por el candidato. Las alianzas también son denominadas coaliciones ad hoc o pactos de colaboración. 
sobre coaliciones y explora los motivos que las alientan (las reglas electorales y la fragmentación del sistema de partidos) e incluye la presentación de resultados de las elecciones de 2011 y 2015 (KAS, Pontificia Universidad Javeriana \& Moe, 2017). Del mismo modo, se han explorado las perspectivas teóricas sobre coaliciones y se analizan elecciones de alcaldes: se suele concluir que coaligarse es un ejercicio rentable y que los partidos son más efectivos cuando están acompañados (Basset y Franco, 2020); se considera que son parciales por cuanto no hay un análisis del conjunto de las coaliciones y/o alianzas en las elecciones de gobernadores realizadas bajo el nuevo marco normativo. Esto no es una valoración negativa, solo señala los alcances de los artículos, capítulos de libros e informes periodísticos generales.

Este artículo retoma la literatura existente y se propone contribuir a responder algunas de estas preguntas mediante el análisis de las elecciones que se han llevado a cabo bajo los cambios institucionales que regulan las coaliciones en el país, suma evidencias empíricas a favor del enfoque analítico que es descrito en la primera parte del texto. Se analiza el periodo 2011-2019, desde que se empezó a aplicar la normatividad que consagra y regula las acciones conjuntas de los partidos mediante la figura de los coavales hasta las más recientes elecciones. El análisis se lleva a cabo a partir de cinco enunciados con las respectivas evidencias y que constituyen el aporte central: (1) la estrategia electoral dominante en las elecciones de gobernadores es la coordinación entre partidos, facciones y políticos que se concreta en coaliciones y alianzas y tienden a imponerse las primeras $^{2}$; (2) las coaliciones son, básicamente, para maximizar votos; (3) las coaliciones son cada vez más exitosas; (4) en la mayoría de acciones conjuntas se presentan alianzas divergentes, los socios varían de un departamento a otro y los que son aliados en uno son rivales y competidores en otros, de esto se exceptúan los partidos con más orientación ideológica contrapuestos de izquierda y derecha, y no se presentan coaliciones o alianzas "contra natura" (las que se coaligan partidos alejados ideológicamente); (5) en el predominio de coaliciones y alianzas inciden tanto las reglas electorales como el incremento de la competencia y las características organizativas de los partidos. ${ }^{3}$

La metodología utilizada para corroborar estos enunciados empíricamente es propia de los análisis electorales, en este caso se procedió de la siguiente forma. Se hizo acopio de la información sobre las candidaturas y los resultados de las elecciones en los 32 departamentos en 2011, 2015 y 2019 (96 elecciones, sin incluir las elecciones atípicas que se convocan por ausencia absoluta del mandatario por destitución o fallecimiento). Se identificaron los gobernadores elegidos mediante alianzas y coaliciones en cada elección (las alianzas fueron rastreadas a través de la prensa local y nacional, y las coaliciones están identificadas oficialmente en la inscripción de los candidatos). Se ponderaron respecto a las gobernaciones partidistas, las alianzas y las coaliciones respecto al total de candidaturas identificando los partidos de cada una de ellas (esta información se consignó en una tabla por cada elección). Mediante gráficos hechos con el programa Gephi se presentaron las alianzas y coaliciones, se incluyeron los departamentos y los partidos que se aliaron o coligaron en cada caso, de tal forma que se puede apreciar la densidad y los nexos partidistas en cada caso. ${ }^{4}$ Se utilizó la información institucional de la Registraduría Nacional del Estado Civil sobre las elecciones, los resultados y la inscripción de los candidatos, esta información se complementó con otra procedente de prensa nacional, regional y portales de internet. ${ }^{5}$ Se analizó el marco normativo sobre coaliciones y sus cambios, se dio cuenta del nivel del sistema de partidos y se utilizó el índice de Número efectivo de Partidos y el Índice de Concentración para

${ }^{2}$ Brevemente definimos a los partidos políticos a partir de Giovanni Sartori como "cualquier grupo político identificado por una etiqueta oficial que se presenta a unas elecciones (libres o no) y que puede colocar a sus candidatos a cargos públicos" (1980:92), adicionando que estas agrupaciones tienen así sea en términos mínimos o meramente formales y declarativos, un componente ideológico o programático y una estructura organizativa. También con Sartori definimos a las facciones como las subunidades partidistas que constituyen grupos de poder y que carecen de organización o esta es muy endeble, pueden ser más coyunturales y dependen totalmente de liderazgos personalistas (Idem).

${ }^{3}$ Un sexto argumento importante se refiere al tipo de coaliciones según las motivaciones de los actores, lo cual rebasa el alcance de este trabajo. La hipótesis indicaría que se trata de las alianzas y coaliciones que tienen una doble motivación: son pragmáticas transaccionales y se proponen acceder al reparto de recursos estatales (cuotas burocráticas, contratos, beneficios para allegados), lo que se deriva del predominio de partidos y facciones clientelistas.

${ }^{4}$ Es un programa de visualización de redes, una plataforma interactiva de código abierto para la visualización y exploración de todo tipo de redes y sistemas complejos con gráficos dinámicos y jerárquicos. Disponible en: http://gephi.org/users/download/

${ }^{5}$ Se prefirió citar todas las fuentes al final para no cargar de tantas referencias el texto. 
presentar el número de competidores y el nivel de fragmentación partidista ${ }^{6}$. También se recurrió a fuentes secundarias y estudios previos para caracterizar a los partidos.

En la estructura del artículo se consideran los conceptos de coaliciones y alianzas electorales y los factores asociados a ellas (primera parte), el cambio institucional y su contexto (segunda parte), y las dimensiones de ambas formas de coordinación estratégica y sus características principales en las tres elecciones (tercera parte). Por último, se plantean algunas conclusiones y una reflexión sobre las implicaciones que tienen estas formas asociativas en la responsabilidad política, la representación y las dinámicas internas de los partidos.

\section{La coordinación estratégica y los factores asociados a ella}

Las alianzas y las coaliciones electorales son formas de coordinación estratégica, esto es, acciones mediante las cuales los partidos políticos (o facciones o sectores de estos) deciden presentarse juntos a unas elecciones a través de una candidatura única con el propósito de aumentar sus probabilidades de éxito, de lograr unidos lo que resulta más difícil o poco probable de obtener si actúan solos (Cox, 1997). De forma más concreta, las coaliciones y las alianzas se dan cuando un conjunto de partidos políticos (o sectores, tendencias o facciones, incluso un político independiente, agregamos) acuerdan perseguir metas comunes (para el caso, ganar una elección) y actúan de forma conjunta y/o comparten el poder. Para ello reúnen recursos para lograrlo y distribuyen los beneficios si resultan ganadores (Golder, 2006; Chasquetti, 2008).

La presencia de coaliciones y alianzas depende de ciertos factores que las posibilitan o limitan, que las incentivan o desincentivan. En la literatura especializada se suelen incluir dos factores: (A) las instituciones, es decir, las reglas electorales y, (B) las características de la competencia política, el número de actores políticos y de sus interacciones, específicamente la fragmentación partidista (Cox,
1997; Golder, 2006; Reynoso, 2011; Méndez, 2012; Strøm, 2013; Clerici \& Scherlis, 2014; Olmeda, 2016). Algunos análisis incluyen también la proximidad ideológica entre las facciones o partidos como un factor importante, aunque hay menos acuerdos al respecto (Reniu, 2001; Reynoso, 2011). Hay otro factor que es importante y suele ser poco considerado en los análisis, (C) las características de los partidos políticos y su institucionalización organizativa, especialmente la cohesión interna y el control de la dirigencia nacional de los partidos sobre los políticos regionales. En conjunto estas relaciones se pueden ilustrar de la siguiente forma:

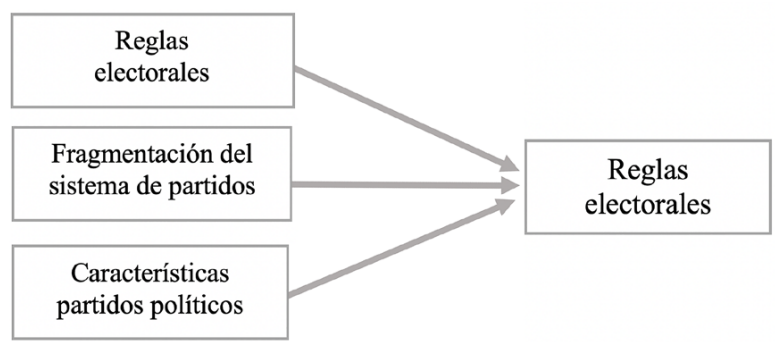

En cuanto al primer factor, (A), las coaliciones existen en sistemas electorales en los que se permiten y se regulan como una forma de actuación conjunta de los partidos y hay ciertas reglas que incentivan la coordinación estratégica. Por una parte, que se permita la inscripción de candidatos por varios partidos, sea que se establezca o no la corresponsabilidad en la gestión y el acceso de los partidos coligados al manejo de la administración de la entidad territorial. Por otra parte, el tipo de reglamentación sobre la coherencia o divergencia de la conducta de los partidos en las distintas unidades territoriales (estados, provincias, departamentos, municipios), si se permite o no que un partido participe en coaliciones diferentes en localidades en un mismo proceso electoral. La reglamentación depende de las características de los partidos del respectivo país, en donde son muy cohesionados y estables, se propugna por la uniformidad y, por el contrario, si predominan los partidos con débil estructuración entre el nivel nacional y regional se permiten las asociaciones divergentes (Fleischer, 2007; Machado, 2009; Méndez, 2012; Clerici \& Scherlis, 2014; Olmeda, 2017). En tercer lugar, si se

${ }^{6} \mathrm{El}$ número efectivo de partidos es la medida del número de partidos $(\mathrm{N})$ ponderado por su tamaño, ya sea en votos, o en escaños, donde Pi es la proporción de votos o escaños de cada partido i, esto es: NEP=1// Pi2. Pondera el tamaño de los partidos y aquellos que son muy pequeños o marginales no cuentan, por ello es más acertado que considerar el número absoluto de partidos que participan en las elecciones. (Laakso y Taagepera 1979). El Indice nando la votación de los dos partidos mayoritarios, de fal forma que entre mayor es el índice menos alta votación hay poca fragmentación, pues se reduce el espacio para la presencia de otros partidos, mientras que esfe índice es muy bajo, significa que el electorado está muy fragmentado, muy distribuido entre muchos pequeños partidos. 
financian las campañas de candidatos coligados o solo de los partidos (Méndez, 2012); en cuarto lugar, si se permite o no la doble militancia y con ello se regulan las alianzas y coaliciones y la pertenencia de un político a más de un partido. En quinto lugar, si en las elecciones departamentales solo hay ganadores absolutos o hay compensaciones a los perdedores como la asignación de curules a quienes ocupen segundos lugares, lo que hace que los beneficios derivados de esta posición incentiven a que algunos partidos se asocien para no quedar excluidos de todo del juego político.

Respecto al segundo factor, (B), se considera que las coaliciones son más frecuentes en la medida en que aumentan los actores (partidos) en competencia, hay mayor fragmentación y cambia la interacción entre los partidos (sistema de partidos). En sistemas multipartidistas con alto nivel de fragmentación hay mayor competencia y más dificultad para que un partido gane solo las elecciones, mientras que en sistemas bipartidistas o con multipartidismo moderado hacen presencia pocos partidos y de mayor tamaño que pueden ganar las elecciones sin necesidad de coligarse ni de compartir los beneficios derivados del triunfo. Diversos estudios han establecido que los partidos políticos coordinan sus acciones con candidaturas comunes cuando hay mayor competencia y los electorados están más fragmentados, de tal forma que con la acción conjunta se incrementa su probabilidad de éxito (Cox, 1997; Reynoso, 2011; Méndez, 2012; Miño, 2015). Se asocia el escenario electoral, su volatilidad, la mayor o menor estabilidad, la aparición o desaparición de actores importantes con la actuación conjunta de los partidos. La mayor competencia en los sistemas multipartidistas aumenta el riesgo de perder posiciones, de quedarse por fuera del acceso a recursos estatales, de quedar durante un cuatrienio o sexenio al margen. En algunos países de América Latina es claro que las coaliciones y alianzas responden al aumento del pluralismo y de la competitividad que suelen ser el producto de progresivas aperturas de los sistemas políticos en el marco de la descentralización política. La formación de coaliciones surge como una estrategia que aumenta las posibilidades de éxito electoral (Espinal, 2010; Méndez, 2012; Benito, 2015; Olmeda, 2016).

En las características del escenario partidista y en la competencia inciden los cambios institucionales, específicamente las aperturas democratizadoras y los cambios que favorecen el pluralismo y la presencia de más partidos y/o de candidatos independientes. Los cambios pueden hacer que un partido, que era marginal o un nuevo partido, incremente su electorado y se convierta en un actor más relevante $\mathrm{y}$, por ende, más atractivo para otros partidos como alternativa de coalición. Si el sistema de partidos se fragmenta mucho y no hay partidos dominantes, las coaliciones son obligatorias y se incrementa la incertidumbre. Los partidos políticos más grandes se alían con otros cuando el caudal electoral de estos últimos ha variado para mejor $y$, por lo tanto, su percepción es que formando un frente electoral con ellos mejoran las oportunidades de derrotar a los competidores (Cox, 1997). Asimismo, partidos pequeños se pueden asociar para intentar derrotar a un partido mayor o a una coalición dominante.

Sobre el tercer factor, (C), también inciden en la presencia de alianzas y coaliciones las características de los partidos. El tamaño de los partidos, porque en un sistema muy fragmentado ninguno tiene el tamaño suficiente para aspirar a ganar solo, no hay un partido claramente dominante y se debe buscar socios electorales, mientras que para los partidos muy pequeños buscar unirse a coaliciones les permite ser viables y no desaparecer (Ibenskas, 2015). El carácter ideológico o pragmático de la dirigencia de un partido también incide en la conformación de coaliciones. En ciertas condiciones de competitividad, los partidos pragmáticos, clientelares o que compiten por el botín tienen mayor inclinación a coligarse de forma genérica con las mejores alternativas, sin considerar su proximidad ideológica, según sean las condiciones específicas, la composición partidaria de las alianzas cambia o podría cambiar de una elección a otra, según los cambios en el mercado electoral (Reniu, 2001; Reynoso, 2011; Clierici, 2013); y viceversa, los partidos con mayor contenido ideológico son más reacios a coligarse con los partidos que se ubiquen muy lejanos de su posición en el espectro ideológico, incluso pueden preferir perder una elección a unirse con un opositor, se supone que este tipo de partidos se inclinan a formar alianzas con sus vecinos ideológicos (Koessl, 2001; Lyne, 2008). En todo caso, asumiendo que quienes hacen parte de una coalición esperan obtener una parte de los recursos, de las posiciones y de las cuotas de poder si esta resulta ganadora (Gamson, 1961), las coaliciones en sistemas con partidos clientelares, 
predominantemente pragmáticos y transaccionales son más recurrentes, pues la orientación ideológica deja de ser un obstáculo y se amplía el espectro de los partidos con los que se pueden actuar de forma conjunta.

Asimismo, las coaliciones y alianzas se ven influidas por el nivel de nacionalización de los sistemas de partidos y la correspondiente regionalización de la organización de los partidos: cuando no hay nacionalización, los partidos son muy autónomos y los dirigentes de los departamentos deciden con quién y cuándo hacer alianzas y coaliciones. En estos casos no hay congruencia entre las formas de actuar de la dirigencia nacional y la de los políticos regionales, ampliamente independientes y $\sin$ control, de ahí se derivan las coaliciones divergentes (Cosano, 2009).

En el caso de Colombia, las reglas electorales (A) solo entran en juego en las dos últimas décadas. Con el propósito de reducir la alta fragmentación o atomización subsiguiente a la Constitución de 1991, la reforma de 2003 se propuso racionalizar y reducir el número de partidos que se había multiplicado de forma extraordinaria (en las elecciones de 2002, últimas bajo las reglas anteriores a la reforma, se presentaron candidatos por 73 etiquetas partidistas, muchas de ellas efimeras, sin relevancia electoral, sin estructuras ni continuidad). En el marco de sistemas de partidos muy fragmentados, los partidos, facciones y movimientos políticos actuaron estratégicamente a través de alianzas informales, de acuerdos entre políticos que pactaban apoyos intercambiables por concesiones de parte del gobernante electo, en el caso de que ganaran las elecciones. Solo desde el año 2009 se empezaron a reglamentar estas dinámicas asociativas muy extendidas. Anteriormente, como desarrollo de la Constitución, la Ley 130 de 1994, Estatuto Básico de Partidos y Movimientos Políticos, lo único que estableció fue que los partidos y movimientos que formaran coaliciones determinarian previamente la forma de distribución de los aportes estatales a la campaña para evitar perder el derecho a la reposición estatal de gastos (Art.13). Suponía que podría haber coaliciones, pero no las reglamentaba. De hecho, lo que sucedía era que había acuerdos informales, pero los candidatos se registraban por un solo partido, movimiento o grupo significativo de ciudadanos como candidatos independientes y en cada elección se coligaban de manera informal facciones, partidos, movimientos y, en algunos departamentos, clanes políticos

Las reglas eran ambiguas y poco claras. Solo mediante una nueva reforma política (la Ley 1457 de 2011) que desarrolló múltiples aspectos relacionados con el Acto Legislativo 01 de 2009 se reglamentaron las coaliciones. Los partidos y movimientos políticos con personería jurídica coaligados entre sí y/o con grupos significativos de ciudadanos podrían inscribir candidatos de coalición para cargos uninominales. Se determinó que antes de la inscripción del candidato la coalición debía establecer el mecanismo mediante el cual se elegiría al candidato, el programa que se iba a presentar, cómo se financiaría la campaña y cómo se distribuirá entre los distintos partidos y movimientos que conforman la coalición la reposición estatal de los gastos, así como los sistemas de publicidad y auditoría interna. Igualmente, se debía establecer el mecanismo mediante el cual formarán la terna en los casos en que hubiere lugar a reemplazar al elegido. Se determinó que el acuerdo de coalición tenía un carácter vinculante $\mathrm{y}$, por tanto, los partidos y movimientos políticos y sus directivos, y los promotores de los grupos significativos de ciudadanos no podrán inscribir, ni apoyar candidato distinto al que fue designado por la coalición (Art. 29).

Se reguló así una práctica habitual de los acuerdos informales, y en lo sucesivo, convivirían estas alianzas con las coaliciones formales, aunque gradualmente se fueron imponiendo las coaliciones. Posteriormente, mediante el Estatuto de la Oposición (Ley 1909 de 2018) se estableció que el segundo candidato en votos a la presidencia y vicepresidencia, y a alcaldías y gobernaciones tendría derecho a ocupar una curul en la respectiva corporación pública (Senado, Cámara de Representantes, Asambleas departamentales y Concejos Municipales, respectivamente). Con esta nueva norma, el segundo ya no es un perdedor absoluto y obtiene una posición, se mantiene en el juego político y accede a los medios, a espacios y a los beneficios del cargo. De este conjunto de reglas, también la prohibición de la reelección inmediata incentiva las coaliciones. Con partidos divididos, poco estructurados y gobernadores elegidos mediante alianzas o grupos, significativo de ciudadanos, no hay posibilidad de premiar o castigar a un partido. Cada cuatro años se reconfigura el mercado electoral y, en un contexto de alta fragmentación, empieza el juego de coaliciones y alianzas. 
Respecto a (B), la fragmentación del sistema de partidos, después de la Constitución Política de 1991, de la apertura democrática y las normas laxas para conformar partidos y la ausencia de umbral electoral, los partidos Liberal y Conservador mantuvieron sus lugares de preminencia y sus mayorías, pero aparecieron numerosas agrupaciones políticas y se transitó hacia un multipartidismo más o menos atomizado según las dinámicas de cada departamento. Posteriormente, con las reformas de la década del 2000, especialmente con el umbral electoral, la prohibición de la doble militancia y las listas únicas, se dio un doble movimiento: los partidos Liberal y Conservador se escindieron $\mathrm{y}$ perdieron su lugar de preminencia, y muchos políticos nacionales y regionales se reagruparon en nuevos partidos, algunos fueron efimeros y otros se estabilizaron (Duque, 2012 \& 2018). A su vez, se hicieron más visibles las organizaciones de izquierda, las minorías religiosas y organizaciones regionales, y se configuró un multipartidismo altamente fragmentado que oscila entre 10 y 17 partidos. El resultado de estos reacomodos y de la creación de partidos y movimientos fue la alta fragmentación y la competencia entre partidos minoritarios, sin que en la gran mayoría de departamentos se consolidara un partido con mayorias suficientes para imponerse solo (Milanese \& Jaramillo, 2014; Milanese, Abadía y Manfredi, 2016; Basset \& Franco, 2020).

En cuanto al tercer factor (C), en los últimos tres lustros un aspecto central de los partidos políticos colombianos ha sido su debilidad organizativa, esta se expresa en la poca articulación vertical, es decir, en la desarticulación de los niveles central y regional, y la gran autonomía de la clase política de los departamentos respecto de la dirigencia nacional. Los políticos regionales actúan de forma autónoma y estructuran micro organizaciones que auto gestionan y lideran ellos mismos (en ocasiones como empresas familiares o clanes políticos), construyen sus redes electorales, se financian con recursos que no son controlados por el partido, interactúan con otras facciones y partidos por su propia iniciativa y sin control alguno por parte de las respectivas direcciones nacionales. Impera la débil institucionalización organizativa en la mayoría de partidos, y esto hace que cada partido sea, en realidad, una agregación de facciones regionales, cuyos dirigentes con frecuencia han transitado por varios partidos (Botero \& Alvira, 2012; Duque, 2007 \& 2019; Dávila, 2020). ${ }^{7}$

Otro aspecto es el carácter transaccional y los intereses específicos, de clanes, de clientelas, de redes de políticos cuyo propósito central es la apropiación de los recursos públicos, de aquí se desprende la principal motivación de la mayoría de partidos, facciones, movimientosy políticos regionales (Dávila, 2020). Por lo anterior, la mayoría de partidos y facciones no se diferencian ideológicamente entre sí, por ello predominan las coaliciones pragmáticas, casi indiscriminadas y divergentes: los partidos de oposición situados hacia la centro-izquierda interponen condiciones ideológicas para crear coaliciones con otros partidos, mientras que los grandes partidos Liberal, Conservador y los de más reciente creación, se coligan orientados por criterios de maximización de votos e intereses de clientela y de apropiación, y reparto de recursos (Wills, Battle \& Barrero, 2012; Botero \& Alvira, 2012; Milaneses, 2014).

Como se verá en los tres siguientes apartados, estos tres factores incidieron en el predominio de las coaliciones y las alianzas en las elecciones de gobernadores de 2011, 2015 y 2019.

\section{Las elecciones de 2011 Agregación de votos en contextos fragmentados bajo nuevas reglas}

\section{Los resultados}

Desde el año 2011 el cambio en las reglas de juego sobre coaliciones (la Ley 1457 de 2011), la alta fragmentación partidista y la orientación pragmática de los partidos débilmente articulados, verticalmente incidieron para que las alianzas y coaliciones empezaran a ser la estrategia

${ }^{7}$ En términos de Smiley (1987), los partidos que tienen una alta integración vertical presentan una constante colaboración e interacción entre los diferentes niveles territoriales de la organización (nacional y regional) que se basa en normas y reglas conocidas, acatadas y aplicadas que facilitan la cooperación, y existen directrices nacionales que rigen el funcionamiento organizativo del partido que actúan coordinado y con disciplina. Así mismo, la cooperacion, y existen directrices nacionales que rigen el funcionamiento organizativo del partido que actuan coordinado y con disciplina. Asi mismo, la oferta programatica de los partidos tendera a ser similar en los diferentes niveles de gobierno. En todo caso, los partidos actuan de torma coherente en los partidos con baja integración presentan discordancias entre los niveles nacional y regional, no se pueden identificar orientaciones unánimes ni existe cohesión ni acatamiento de reglas, pues estas no existen o son solo formales. Tampoco existe coherencia ideológica, ni las subunidades territoriales actúan en sus alianzas y coaliciones de forma convergente, son, básicamente, divergentes. Como lo señala Mónica Méndez (2004): "En los partidos con integración vertical elevada las diferentes unidades territoriales desarrollan estrategias electorales dirigidas a grupos sociales similares y establecen alianzas preelectorales o coaliciones con los mismos "socios" independientemente del nivel de gobierno de que se trate. Cuando la integración vertical es escasa hay una mayor heterogeneidad en este ámbito, como resultado de la mayor autonomía de cada unidad territorial de un partido para decidir sobre estos aspectos en función de las características de la competición electoral y partidista en cada territorio" (p. 9). 
predominante en las elecciones de gobernadores departamentales.

Los resultados electorales mostraron un alto predominio de gobernadores elegidos a través de coordinaciones estratégicas. Se formalizaron 5 coaliciones cuyos candidatos fueron inscritos por varios partidos a través de coavales (el 15.6\%), en 19 departamentos se formaron alianzas preelectorales informales exitosas con candidatos avalados por un partido o un grupo significativo de ciudadanos, pero que recurrieron a la agregación de votos de diversa procedencia (el 59.4\%). Así, en conjunto, en 24 departamentos se impusieron candidatos que agregaron electorados de diversos partidos, facciones o movimientos políticos. En 8 departamentos ganaron candidatos partidistas (el 25\%) Ver tabla 1.

Además de este amplio predominio de las gobernaciones, en las que se impuso la coordinación estratégica, estas elecciones presentaron cinco características principales:

(a) Participaron 15 partidos o movimientos políticos. Aunque son muchos partidos, hubo una reducción importante respecto a las elecciones del periodo entre 1991 y 2002, en las que el sistema multipartidista se había atomizado y llegó a contar con 74 partidos en competencia en las elecciones de 2002. Tras la reforma política de 2003 , las nuevas reglas tuvieron un efecto reductor y encauzaron la competencia a través de diversas dinámicas de agregación de pequeños partidos, desaparición de otros y aparición de nuevas agrupaciones por reubicación de dirigentes de diversa procedencia política. ${ }^{8}$ Algunos partidos venían de décadas anteriores y tenían alcance nacional, como el Liberal y el Conservador, con más de siglo y medio de historia; Autoridades Indígenas de Colombia y Alianza Social Indígena, surgidos en 1991; Cambio Radical, partido de origen liberal creado en 1997; Convergencia Ciudadana, creado en 1997 en el departamento de Santander y que se había expandido a otros departamentos (desde 2011 cambió el nombre por Partido de Integración nacional, PIN), y el Movimiento de Renovación Absoluta, MIRA, una agrupación religiosa cristiana creada en el año 2000. Otros eran de más reciente creación, como el Polo Democrático Alternativo, partido de izquierda creado en 2005 por agregación de diversos movimientos y organizaciones sociales, el Partido Social de Unidad nacional (Partido de la U), creado el mismo año también por agregación de políticos ex liberales y ex conservadores; el Partido Verde, cuyo antecedente es también de 2005 en la agrupación Opción Centro, que desde 2010 tomó su nuevo nombre. Los otros tres partidos eran agrupaciones regionales de alcance muy regional: Apertura Liberal, el Movimiento de Inclusión y Oportunidades, MIO, y Afrovides. ${ }^{9}$

(b) Los grandes partidos fueron los que más se incorporaron a coaliciones y a alianzas electorales ganadoras, la mayoría de las veces entre sí: Cambio Radical hizo parte de 4 coaliciones y 9 alianzas; el Partido Social de Unidad Nacional de 2 y 10; el Conservador de 5 y 9; el Liberal de 4 y 13 y el Partido Verde de 2 y 4 , respectivamente. Los cuatro últimos obtuvieron, además, 1 gobernación sin coaliciones ni alianzas. Estos partidos mantienen sus posiciones de poder (individual o compartido) en la mayoría de departamentos, lo cual corresponde también con su presencia nacional y sus mayorías en el Congreso de la República. Otros partidos pequeños se incorporaron a coaliciones y alianzas ganadoras: la Alianza Social Independiente hizo parte de 3 coaliciones y 3 alianzas (en 3 departamentos su candidato las encabezó); el Partido de Integración Nacional, PIN, hizo parte de 7 alianzas electorales ganadoras; Autoridades Indígenas de Colombia, AICO, hizo parte de una alianza y una coalición, y ganó una gobernación solo; Afrovides hizo parte de 1 coalición y 1 alianza, y ganó una gobernación solo; Convergencia Ciudadana se incorporó a una alianza; Apertura Liberal a 1 alianza; el Movimiento de Inclusión y Oportunidades participó de 2 coaliciones (una la encabezó).

(c) Predominaron las alianzas y coaliciones no homogéneas o divergentes. Como no hay integración

\footnotetext{
${ }^{8}$ Mediante el Acto legislativo 01 de 2003, la reforma política estableció normas que tenían un propósito reductor del gran número de partidos que en el 2002 llegó a ser de 74 , especialmente el umbral electoral ( $2 \%$ del total de votos en elecciones de Senado y la mitad del cociente electoral en elecciones para Camara, Concejos Municipales y Asambleas departamentales), la prohibición de la doble militancia, las liștas únicas (combinadas con el voto preferente, lo que mantuvo la división grupal al interior de los partidos y la reproducción de los feudos electorales regionales).

${ }^{9}$ Apertura Liberal fue creado en 1993 en Norte de Santander, ha sido marginal en la política nacional y en las elecciones de 2010 avaló a dos candidatos elegidos a la Cámara de Representantes en Putumayo y en Casanare. El Movimiento de Inclusión y Oportunidades, MIO, fue una reconversión del Movimiento Popular Unido, MPU, creado en el 2001 por el exsenador Carlos Herney Abadía, uno de los congresistas condenador por el escándalo de penetración de dineros del cartel de Cali en la política en las elecciones de 1990-1994. En 2010 este partido obtuvo una de las curules de las minorías afrodescendientes en la Cámara de Representantes (Heriberto Arrechea), por tener una curul podía solicitar reconocimiento legal, por lo que el Consejo Nacional Electoral se la otorgó en agosto de 2010 . Afrovides fue otro movimiento de negritudes, con sede en Sucre. En 2010 fue elegido con su aval Yahir Acuña por la circunscripción especial de esta minoría racial en Cámara, en estas elecciones ganó la gobernación en Casanare con Nelson Ricardo Mariño (ver: Semana, agosto 30 de 2011).
} 
vertical de los partidos ni una fuerte cohesión del centro con la periferia (los departamentos) y los partidos no son coherentes en sus actuaciones y predomina el pragmatismo, se dieron uniones con partidos diferentes según las condiciones específicas en cada departamento.

Lo expresado en los puntos b y c se ilustra en la gráfica 1. Se usa el programa Gephi que permite representar la trama de interacciones mediante coaliciones y alianzas exitosas. De cada partido salen conexiones hacia los departamentos en los que hicieron parte de coaliciones (Antioquia, Atlántico, Bolívar, Caquetá, Cauca, Cesar, Córdoba, Huila, Guajira, Magdalena, Meta, Norte de Santander, Guindío, Risaralda, Santander, Sucre, Tolima, Valle del Cauca y Vichada), y en color verde en los que hicieron parte de alianzas informales (Boyacá, Caldas, Cundinamarca, Chocó y Nariño). Los partidos más grandes son los que más conexiones tuvieron, $\mathrm{y}$ se ubican en el centro (muchas interacciones entre sí y muchas divergentes), mientras los que participaron en menos coaliciones y alianzas se presentan más aislados (como el MIRA, Afrovides, AICO, PDA).

Gráfico 1. elección de gobernadores de 2011. Trama de coaliciones y alianzas entre partidos.

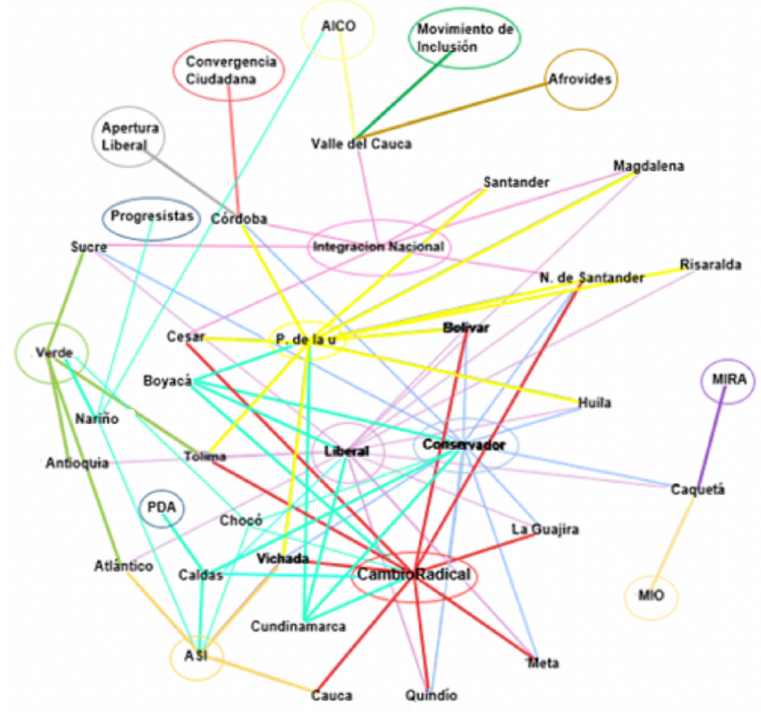

Indica las gobernaciones mediante coaliciones formales. Los demás colores son alianzas electorales informales.

Fuente: Elaboración propia con información de la tabla 1

(d) Predominan los partidos de orientación pragmática y transaccional, y los partidos con más claro contenido ideológico no se coligaron ni se aliaron, o lo hicieron muy poco, se expresa así un rechazo a las agrupaciones políticas percibidas como adversarias y contradictoras. Este fue el caso del Polo Democrático Alternativo, que solo hizo parte de una coalición ganadora (en Caldas, con Guido Echeverry Piedrahita del movimiento Alianza Gobierno de todos y para todos), se dividió en el apoyo a candidatos en Nariño (un sector apoyó a Germán Chamorro de la Rosa de la coalición Unidad Regional por un Nariño Mejor) y avaló candidatos en 8 departamentos, pero en ninguno ganó (perdió la única gobernación que tenía en Nariño). A su vez, el Movimiento Independiente de Renovación Absoluta, MIRA, que no hizo parte de coaliciones, ganó en solitario la gobernación de Caquetá (se le unió eventualmente el MIO) y avaló candidaturas no exitosas en 4 departamentos.

(e) También hubo alianzas perdedoras en departamentos con elecciones muy competitivas: en La Guajira (de los partidos Social de Unidad nacional, Conservador, Liberal, Verde), en Caldas (Coalición B, Partido Social de Unidad Nacional, una facción del Partido Conservador), en Huila (otras dos coaliciones, una de los partidos Liberal y Cambio Radical, y la otra de Partido Conservador, Alianza Verde y ASI), en Nariño (Partido Social de Unidad nacional, un sector del PDA, Conservador, Liberal), y en el Valle del Cauca (conformada por los partidos Liberal, Social de Unidad nacional, Cambio Radical y una facción del Partido Conservador). De igual forma, otros partidos pequeños avalaron candidatos perdedores en varios departamentos: Afrovides, PIN y el MIO avalaron candidatos en 5 departamentos, AICO en 6 y ASI en 5 departamentos (fueron acusados de vender avales de forma indiscriminada a Gobernaciones, Alcaldías, Concejos Municipales y Asambleas departamentales).

\section{Fragmentación partidista, mayor competencia y alianzas electorales}

Como ya se mencionó, a nivel nacional el sistema de partidos transitó hacia el multipartidismo, y en el nivel regional departamental se empezó a reflejar tras la reforma política de 2003. En este análisis de las coaliciones y las alianzas electorales se constata la fragmentación del sistema de partidos, midiéndolo mediante el Número Efectivo de Partidos Electorales (NEPE) y el Îndice de Concentración (IC) en elecciones de las asambleas departamentales. 
Tabla 1. Coaliciones y alianzas electorales en elección de gobernadores de 2011.

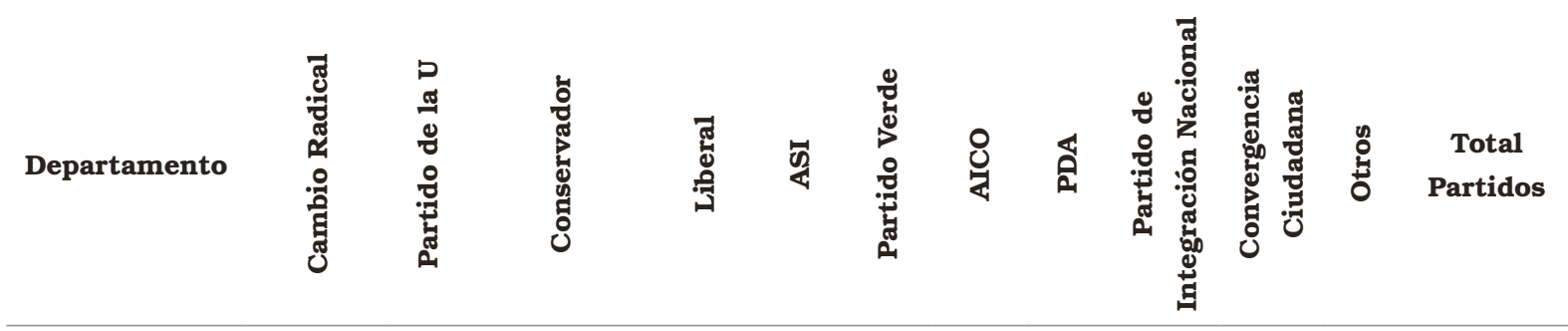

Gobernaciones mediante coaliciones formales

\begin{tabular}{|c|c|c|c|c|c|c|c|c|c|}
\hline Boyacá & 1 & 1 & 1 & 1 & & & & & 4 \\
\hline Caldas & 1 & & $1^{*}$ & 1 & 1 & & 1 & & 5 \\
\hline Cundinamarca & 1 & 1 & 1 & 1 & & & & & 4 \\
\hline Chocó & 1 & & 1 & & 1 & 1 & & & 4 \\
\hline Nariño & & & & & 1 & 1 & 1 & 1 & 6 \\
\hline
\end{tabular}

Gobernaciones mediante alianzas electorales informales

\begin{tabular}{|c|c|c|c|c|c|c|c|c|c|c|}
\hline Antioquia & & & & 1 & & 1 & & & & 2 \\
\hline Atlántico & & & & 1 & 1 & 1 & & & & 3 \\
\hline Bolivvar & 1 & $1^{\star}$ & $1^{*}$ & 1 & & & & & & 4 \\
\hline Caquetá & & & $1^{*}$ & $1^{*}$ & & & & & 2 & 4 \\
\hline Cauca & 1 & & & & 1 & & & & & 2 \\
\hline Cesar & 1 & 1 & & & & & 1 & & & 3 \\
\hline Córdoba & & 1 & $1^{*}$ & & & & 1 & 1 & 1 & 5 \\
\hline Huila & & 1 & $1^{*}$ & $1^{*}$ & & & & & & 3 \\
\hline La Guajira & 1 & & $1^{*}$ & $1^{\star}$ & & & & & & 3 \\
\hline Magdalena & & 1 & & $1^{\star}$ & & & 1 & & & 3 \\
\hline Meta & 1 & & 1 & 1 & & & & & & 4 \\
\hline N. Santander & 1 & $1^{\star}$ & $1^{*}$ & 1 & & & 1 & & & 5 \\
\hline Quindío & 1 & & 1 & $1^{\star}$ & & & & & & 2 \\
\hline Risaralda & & 1 & & 1 & & & & & & 2 \\
\hline Santander & & 1 & & & & & 1 & & & 2 \\
\hline Sucre & & & 1 & 1 & & 1 & 1 & & & 3 \\
\hline Tolima & $1^{*}$ & 1 & & 1 & & 1 & & & & 4 \\
\hline Valle del Cauca & & & & & & 1 & 1 & & 2 & 4 \\
\hline Vichada & 1 & 1 & 1 & & 1 & & & & & 4 \\
\hline \multicolumn{11}{|c|}{ Gobernaciones mediante alianzas electorales informales } \\
\hline Amazonas & & & & & & 1 & & & & 1 \\
\hline Arauca & & 1 & & & & & & & & 1 \\
\hline Casanare & & & & & & & & & 1 & 1 \\
\hline Guainía & & & & 1 & & & & & & 1 \\
\hline Guaviare & & & & & 1 & & & & & 1 \\
\hline Putumayo & & & 1 & & & & & & & 1 \\
\hline San Andrés y P. & & & & 1 & & & & & & 1 \\
\hline Vaupés & & & & & & 1 & & & & 1 \\
\hline
\end{tabular}

Otros: en Córdoba, Apertura Liberal; en Valle del Cauca, Afrovides y Movimiento de Inclusión y Oportunidades, MIO; en Caquetá, Movimiento MIRA y Movimiento MIO; en Casanare, Afrovides; en Nariño, Progresistas.

Fuente: elaboración propia con base en Registraduría Nacional del Estado Civil y las fuentes citadas en cada caso. 
Teniendo en cuenta lo planteado en la primera parte, el predominio de las alianzas y coaliciones exitosas en elecciones de gobernadores está asociado a tres factores: a las reglas electorales (prohibición de la reelección inmediata; la posibilidad de inscribir candidatos por varios partidos coligados; las candidaturas independientes a través del respaldo de firmas); las características de los partidos políticos (divididos, poco cohesionados en sus niveles nacional y departamental, alta autonomía de los políticos en los departamentos, pragmáticos y mayoritariamente clientelistas), y la alta fragmentación partidista.

Como se ilustra en la tabla 2, en todos los departamentos había un sistema de partidos multipartidista con alta fragmentación, esto es, con un NEPE alto, cuyo valor más bajo fue de 3.82, el máximo de 8.94 y un promedio nacional de 6.12 ; y con IC que en ningún caso superó el $50 \%$. Por lo anterior, en ningún departamento había un partido dominante con capacidad de obtener mayorias absolutas solo, lo cual incentivó la coordinación estratégica entre partidos, movimientos políticos, facciones o sectores dentro de los partidos y candidatos independientes. Hay un dato importante en esta dinámica de fragmentación y alianzas y coaliciones: los ocho departamentos en los que ganaron candidatos de partidos sin coaliciones o alianzas tienen en común ser muy poco poblados, y en ellos el gobernador es elegido con pocos miles de votos, esto hace que los partidos opten por competir solos máxime si predominan las campañas persona-a-persona, el contacto entre candidatos y potenciales electores, y las comunidades es muy directo. Para ilustrar este punto, estas son las votaciones de los ganadores en estos departamentos: Amazonas (7.757), Arauca (34.988), Casanare (54.531), Guainía (4.483), Guaviare (9.729), Putumayo (53.797), San Andrés y Providencia (14.269), y Vaupés (6.206). En estos casos el tamaño de los electorados cuenta.

Tabla 2. Número Efectivo de Partidos en los departamentos 2011(Elecciones de asambleas departamentales).

\begin{tabular}{ccccccccc} 
Departamentos & NEPE & IC & Departamento & NEPE & IC & Departamentos & NEPE & IC \\
\hline Amazonas & 8.94 & 31,4 & Chocó & 5.86 & 43,5 & Putumayo & 6.19 & 46,5 \\
\hline Antioquia & 5.43 & 40,3 & Córdoba & 4.08 & 58,7 & Quindío & 3.82 & 44,9 \\
\hline Arauca & 6.68 & 39,1 & Cundinamarca & 5.85 & 35,1 & Risaralda & 5.02 & 42,1 \\
\hline Atlántico & 4.83 & 43,5 & Guainía & 7.48 & 34,1 & San Andrés & 5.03 & 49 \\
\hline Bolívar & 6.47 & 37,3 & Guaviare & 5.96 & 45 & Santander & 5.66 & 38,9 \\
\hline Boyacá & 4.68 & 46,6 & Huila & 4.32 & 47,3 & Sucre & 4.96 & 40,7 \\
\hline Caldas & 4.50 & 48,5 & La Guajira & 6.58 & 32,6 & Tolima & 5.90 & 38,3 \\
\hline Caquetá & 7.43 & 29,1 & Magdalena & 6.82 & 36,9 & Valle del Cauca & 8.03 & 29,8 \\
\hline Casanare & 7.84 & 32,4 & Meta & 5.12 & 45,6 & Vaupés & 7.38 & 37,7 \\
\hline Cauca & 7.26 & 34,1 & Nariño & 6.76 & 38,6 & Vichada & 7.72 & 33,7 \\
\hline Cesar & 8.31 & 29,5 & N. de Santander & 4.93 & 45,8 & & &
\end{tabular}

Fuente: elaboración del autor con base en estadísticas electorales de la Registraduría Nacional del Estado Civil, elecciones locales de 2011.

Asimismo, las características de los partidos inciden en este predominio de las coaliciones y de las alianzas. Con excepción del partido de Izquierda Polo Democrático Alternativo y del Movimiento de Renovación Absoluta, MIRA, de carácter religioso, cuya orientación ideológica tiene un peso importante en sus decisiones, los demás partidos tienen un carácter más pragmático, y por ello, se asocian casi de forma indistinta con unos u otros partidos. Además, como estos partidos no tienen una articulación fuerte ni existen directivas nacionales que limiten sus decisiones respecto con quién aliarse y en los departamentos sus dirigentes actúan con una gran autonomía decisoria, no hay consistencia respecto a con quién coordinan sus acciones y las alianzas, y coaliciones varían de un departamento a otro. Se combina aquí la naturaleza de estos partidos (transaccional y clientelar), la débil estructuración vertical de los partidos (gran autonomía de sus políticos locales) y un mercado electoral sin partidos dominantes que hace que impere el juego de la agregación de votos como estrategia ganadora. 


\section{Las elecciones de 2015 Se imponen las coaliciones y las alianzas divergentes}

\section{Los resultados}

Respecto a las elecciones de 2011, en el 2015 aumentó el número de coaliciones exitosas y disminuyeron las alianzas, y los gobernadores elegidos por un partido solamente. Las coaliciones pasaron de 5 a 17 de los 32 departamentos (el $53.1 \%$ ), y las alianzas informales ganadoras pasaron de 19 a 12 (el 37.5\%), es decir, hubo una mayor formalización de los pactos partidistas, o entre dirigentes departamentales, aunque las coordinaciones informales siguieron siendo numerosas. La estrategia predominante en elecciones para gobernadores fue la agregación de electorados a través de acciones conjuntas entre partidos, movimientos políticos y/o agrupaciones significativas de ciudadanos que respaldan candidatos independientes a través de firmas. En conjunto aumentaron los mandatarios elegidos mediante coordinaciones estratégicas (90.6\%). En contraste, de igual forma que en las elecciones de 2011, los candidatos partidistas ganaron en muy pocos departamentos, solo en 3 que correspondieron al 9.4\% del total: Amazonas, Caquetá y Guaviare.

Resaltan seis aspectos centrales de estas coordinaciones estratégicas:

(a) De las interacciones asociativas ganadoras hicieron parte 12 partidos, todos tenían presencia nacional (representación en el Congreso de la República). Desaparecieron de este panorama los partidos efímeros MIO, Apertura Liberal y Afrovides, y participaron por primera vez tres nuevas agrupaciones: el Centro Democrático, partido creado en 2013 por Álvaro Uribe Vélez, ex presidente de la república (2002-2010), y su círculo de allegados y apoyos políticos de diversa procedencia $^{10}$; el Movimiento Alternativo Indígena y Social, MAIS, creado en 2013 ${ }^{11}$; y Opción Ciudadana, nuevo nombre del PIN, adoptado desde el año 2013. ${ }^{12}$ Solo dos partidos con curules en el Congreso no aparecieron en coaliciones, ambos regionales: el Movimiento de Integración Regional, con sede en San Andrés y Providencia, y el Partido Por un Huila Mejor.

(b) Como en las elecciones anteriores, los grandes partidos fueron los que más se incorporaron a coaliciones y a alianzas electorales ganadoras: Cambio Radical hizo parte de 10 coaliciones y 10 alianzas, además ganó una gobernación en solitario; el Partido Social de Unidad Nacional de 9 y 8 (en algunos departamentos sus dirigentes se dividieron y apoyaron candidatos diferentes); el Conservador de 4 y 8 (en algunos departamentos dividió sus apoyos a candidatos diferentes); el Liberal de 9 y 6, y ganó una gobernación en solitario; y Alianza Verde de 5 y 2, respectivamente. Como en las elecciones de 2011, incluso en mayor proporción, estos partidos mantuvieron sus posiciones de poder (individual o compartido) en la mayoría de los departamentos, lo cual corresponde también con sus mayorías en el Congreso de la República. En la mayoría de las coaliciones en que participaron aseguraron su éxito y en muy pocos casos se enfrentaron dos coaliciones o alianzas muy fuertes que llevó a la derrota de una de ellas. Los grandes prefieren asociarse antes que perder espacios en las gobernaciones enfrentándose entre ellos.

(c) Los partidos más pequeños entraron también en la lógica de las candidaturas comunes formales e informales, como socios menores pero con capacidad para aportar votos y hacer parte de la distribución del producto del éxito electoral: AICO hizo parte de 3 coaliciones, 2 alianzas y obtuvo una gobernación en solitario (perdió en solitario en 6 departamentos ${ }^{13}$ ); ASI se incorporó a dos coaliciones ganadoras (perdió en solitario en 6 departamentos); Opción Ciudadana hizo parte de 1 coalición y 4 alianzas informales ganadoras (sus candidatos

\footnotetext{
${ }^{10}$ Se incorporaron exintegrantes de los partidos Liberal, Conservador, Social de Unidad Nacional, incluso exguerrilleros del grupo M-19 y ex militantes de partidos radicales de izquierda. En las elecciones de 2014 obtuvo 20 senadores y 19 representantes a la Cámara. Su orientación ideológica es de derecha (Losada y Liendo, 2016)

${ }^{11}$ Según su propia página oficial, en el VII Congreso Nacional Indígena del 2007 se decidió retomar la participación de la dirigencia indígena en la política electoral y avanzar en la construcción de opciones de poder político real para sectores populares y democráticos del país, surgió este año un mandato por parte de las organizaciones indígenas del país para apoyar el nacimiento de un movimiento político que diera directrices y representara los procesos indígenas y sociales. En 2013 en Santander de Quilichao (Cauca), este mandato político recibió el nombre de MAIS - Movimiento Alternativo Indígena y Social; reivindicando la semilla generadora de vida y elemento común de las culturas nativas. En las elecciones de 2014 (MAIS, 2020 ).

${ }^{12}$ Fue la conversión y cambio de nombre del Partido de Integración Nacional, desde 2013 se llamó Opción Ciudadana. Este año los dirigentes del Partido de Integración Nacional (PIN) convocaron su Convención Nacional con él solo propósito de limpiar su reputación y refundar el movimiento por los cuestionamientos por haber recibido a congresistas expulsados de otros partidos por sus vínculos con grupos paramilitares y que terminaron en la cárcel, 3 senadores y 2 representantes a la Cámara. En 2014 el viejo-nuevo partido obtuvo 5 curules en el Senado, todos herederos de clanes políticos con condenados por concierto para delinquir (Semana, abril 12 de 2019).

${ }^{13}$ Autoridades Indígenas de Colombia ha trascendido su carácter de partido étnico y ha entrado en juegos electorales en departamentos en los que hay muy poca poblaciôn indígena, incluso avaló al candidato de Guaviare a Nebio de Jesús Echeverry un cuestionado colonizador y empresario no indígena (El Tiempo, julio 21 de 2015; Ėl Espectador, julio 17 de 2015).
} 
solos perdieron en 3 departamentos en los que se presentaron); MAIS tomó parte de 3 coaliciones ganadoras (sus candidatos solos perdieron en los 7 departamentos en donde se postularon); y el MIRA hizo parte de 7 coaliciones y de 6 alianzas exitosas (participó también en 10 coaliciones y alianzas no ganadoras).

Como se observa en el gráfico 2, en comparación con 2011, hubo más coaliciones que alianzas ganadoras (17 y 12 respectivamente), pero el número de partidos que participaron de las alianzas informales fue mayor al que hizo parte de las coaliciones, por ello el color verde es más notorio que los demás colores. Mientras que sí es claro que son más los departamentos con coaliciones que con alianzas. Son también más visibles los grandes partidos, de donde salen vínculos de coaliciones y alianzas hacia muchos otros y en mayor número de departamentos (especialmente los partidos Liberal, Conservador, de la U, Cambio Radical). Llama la atención el MIRA, que en esta elección se abrió a las interacciones con otros partidos en 7 coaliciones y 6 alianzas ganadoras. Este partido había ganado en 2011 la gobernación de Caquetá con un candidato propio al que se le sumaron tres facciones más en una alianza informal y el cual fue destituido en el 2014 por irregularidades en la contratación.

Gráfico 2. elección de gobernadores de 2015. Trama de coaliciones y alianzas entre partidos.

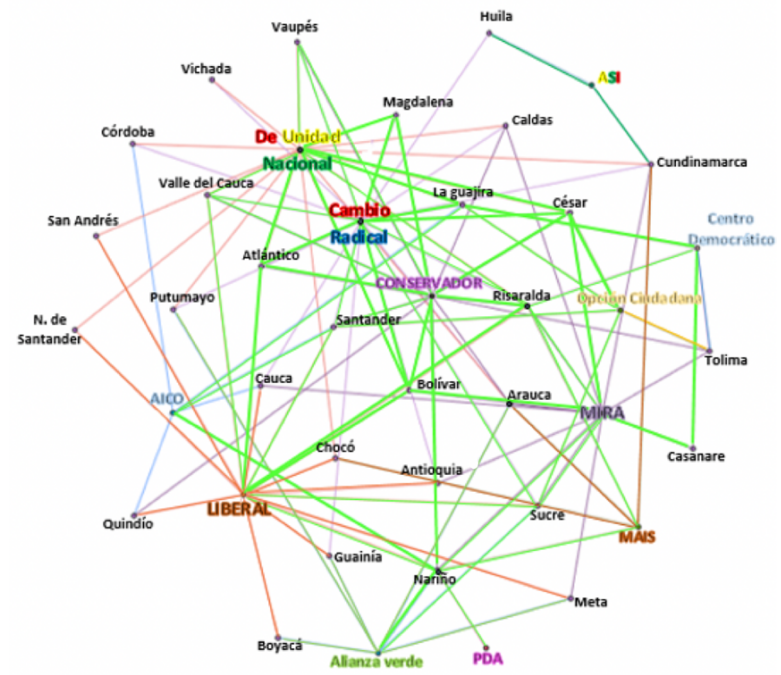

Gobernadores elegidos mediante alianzas. Los demás representan a los gobernadores elegidos mediante coaliciones formales.

Fuente: Elaboración propia con información de la tabla 3 (d) De igual que en el 2011, predominaron las alianzas y coaliciones no homogéneas o divergentes. Esto se explica por el bajo nivel de integración vertical de los partidos y su débil cohesión del centro con la periferia (los departamentos) y la incoherencia en sus actuaciones, en las que predomina el pragmatismo, el clientelismo y los pactos orientados a la distribución de cuotas de poder. Se dieron uniones con partidos diferentes según las condiciones específicas en cada departamento.

(e) Los partidos con claro perfil ideológico se coligaron muy poco, prefieren actuar solos o, eventualmente, con partidos muy cercanos a su ideología, así sean minoritarios. Así sucedió con la izquierda partidista. El PDA participó con su propio candidato y en solitario en 7 departamentos, mientras que una tendencia interna hizo parte de la coalición ganadora en Nariño que, paradójicamente, derrotó a su propio candidato (el sector de este partido que orientaba el exsenador Parmenio Cuellar apoyó al candidato ganador Camilo Romero, quien se presentó con el respaldo de firmas por el movimiento Somos Nariño en alianza con el Partido Verde, AICO, MIRA y facciones de los partidos Conservador y Liberal) ${ }^{15}$. El PDA también hizo parte de coaliciones perdedoras en Cesar (la exguerrillera de las FARC Imelda Daza Cotes, con la Unión Patriótica y la Alianza Verde), en Norte de Santander y Valle del Cauca, también con la Unión Patriótica. Este último partido presentó sus propios candidatos en 2 departamentos (Antioquia y Huila). Igual pasó con la derecha. El Centro Democrático ganó 1 gobernación asociado con el MIRA y participó en otros 12 departamentos con candidato propio y en solitario con la expectativa de irrigar su triunfo electoral en las elecciones de 2014 para Congreso (quedó claro que recién estaba en posicionamiento sin bases en las regiones). Este partido hizo parte de 1 coalición y 3 alianzas ganadoras y se asoció con el Partido Conservador, cercano a sus ideas, en otros dos departamentos, pero también perdió (Guainía y Vichada). No obstante, de forma notoria el MIRA decidió participar en más alianzas y coaliciones que en el 2011, aunque siempre con partidos muy cercanos, conservadores y distantes de la izquierda, especialmente.

(f) Una característica que se mantiene es que solo en algunos departamentos de las regiones de la Amazonia (Amazonas) y la Orinoquia (Caquetá,

${ }^{14} \mathrm{El}$ gobernador Víctor Isidro Ramírez fue destituido por irregularidades en un convenio con una ONG internacional en el sector de la salud (Procuraduría General de la Nación, 2014).

${ }^{15}$ El Espectador, octubre 20 de 2015. 
Casanare, Guaviare) pocos poblados y aislados ganaron candidatos partidistas. Aunque también hay alta fragmentación, en ellos las elecciones se ganan con pocos miles de votos, y ello incentiva las candidaturas individuales (las votaciones de los ganadores fueron, en Amazonas 8.615; en Caquetá, 42.056; en Casanare, 85.500; en Guaviare, 12.840).

Tabla 3. Coaliciones y alianzas electorales ganadoras en elecciones de gobernadores de 2015.

\begin{tabular}{|c|c|c|c|c|c|c|c|c|c|c|c|c|c|}
\hline Departamento & 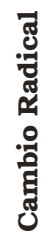 & 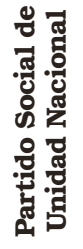 & 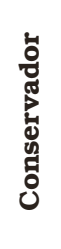 & 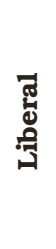 & 忽 & 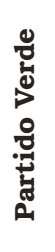 & $\begin{array}{l}0 \\
\text { O } \\
4\end{array}$ & 昌 & 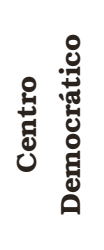 & : & 岕 & ơ & $\begin{array}{c}\text { Total } \\
\text { Partidos }\end{array}$ \\
\hline \multicolumn{14}{|c|}{ Gobernadores elegidos mediante coaliciones formales } \\
\hline Antioquia & 1 & & & 1 & & & & & & & 1 & & 3 \\
\hline Arauca & 1 & 1 & 1 & & & 1 & & & & & 1 & 1 & 6 \\
\hline Boyacá & & & & 1 & & 1 & & & & & & & 2 \\
\hline Caldas & 1 & 1 & $1^{*}$ & & & & & & & & 1 & & 4 \\
\hline Cauca & 1 & & & 1 & & & 1 & & & & 1 & & 4 \\
\hline Córdoba & 1 & 1 & & & & & 1 & & & & & & 3 \\
\hline Cundinamarca & 1 & 1 & & & 1 & & & & & & 1 & 1 & 5 \\
\hline Chocó & & 1 & & 1 & & & & & & & & 1 & 3 \\
\hline Guainía & 1 & & & 1 & & 1 & & & & & & & 3 \\
\hline Huila & 1 & & & & 1 & & & & & & & & 2 \\
\hline Meta & & & & 1 & & 1 & & & & & 1 & & 3 \\
\hline N. de Santander & & 1 & & 1 & & & & & & & & & 2 \\
\hline Putumayo & 1 & 1 & & & & 1 & & & & & & & 3 \\
\hline Quindío & & & 1 & 1 & & & 1 & & & & & & 3 \\
\hline Tolima & & & 1 & & & & & & 1 & 1 & 1 & & 4 \\
\hline San Andrés y P. & & 1 & & 1 & & & & & & & & & 2 \\
\hline Vichada & 1 & 1 & & & & & & & & & & & 2 \\
\hline \multicolumn{14}{|c|}{ Gobernaciones elegidos mediante alianzas } \\
\hline Atlántico & 1 & $1^{\star}$ & $1^{*}$ & 1 & & & & & & & & & 4 \\
\hline Bolivar & 1 & $1^{*}$ & 1 & 1 & & & & & & & 1 & & 4 \\
\hline Casanare & & & & & & & & & 1 & & 1 & & 2 \\
\hline Cesar & 1 & 1 & 1 & & & & & & & 1 & 1 & & 5 \\
\hline La Guajira & 1 & $1^{*}$ & & & & & 1 & & 1 & 1 & & & 5 \\
\hline Magdalena & 1 & 1 & 1 & & & & & & & & & & 3 \\
\hline Nariño & & & $1^{*}$ & $1^{*}$ & & 1 & 1 & $1^{*}$ & & & 1 & 1 & 7 \\
\hline Risaralda & 1 & 1 & 1 & 1 & & & & & 1 & & 1 & 1 & 7 \\
\hline Santander & 1 & & 1 & 1 & & & 1 & & & 1 & & & 5 \\
\hline Sucre & 1 & & & 1 & & 1 & & & & 1 & 1 & & 5 \\
\hline Vaupés & 1 & 1 & 1 & & & & & & & & & & 3 \\
\hline Valle del Cauca & 1 & 1 & 1 & 1 & & & & & & & & & 4 \\
\hline \multicolumn{14}{|c|}{ Gobernaciones elegidas solo por un partido } \\
\hline Amazonas & 1 & & & & & & & & & & & & 1 \\
\hline Caquetá & & & & 1 & & & & & & & & & 1 \\
\hline Guaviare & & & & & & & 1 & & & & & & 1 \\
\hline
\end{tabular}

*Sectores o facciones de los partidos.

Otros: Arauca, Chocó y Cundinamarca; Nariño y Risaralda, el MAIS.

Fuente: elaboración propia con base en Registraduría Nacional del Estado Civil y las fuentes citadas en cada caso e incluida en la bibliografia. 
Más competencia, más coaliciones y menos alianzas electorales

Continuó en estas elecciones la alta fragmentación y se mantuvo el multipartidismo en todos los departamentos. El Número Efectivo de Partidos Electorales (NEPE) para asambleas departamentales fue superior a 4.50, el mayor fue de 9.77, y el promedio nacional de 6.90, de igual forma el IC no fue superior al $50 \%$ en ningún departamento y predominaron los valores inferiores a $40 \%$. (Ver tabla 4).
Como ya se mencionó, las elecciones son disputas entre partidos minoritarios, lo cual hace que sea mayoritaria la coordinación estratégica, por lo cual las coaliciones aumentaron de forma significativa y fueron mayoritarias (17 de 32), y las alianzas se redujeron, pero siguieron siendo numerosas (11 de 32). Estas disputas entre minorías, se constata también en los departamentos en los que ganaron candidatos de solo un partido, todos con un NEPE superior a 7.0 y un IC bajo, con mandatarios elegidos con mayorías relativas: Amazonas (34.9\%); Caquetá (29.4\%), Casanare (46.2\%) y Guaviare (36.7\%).

Tabla 4. Número Efectivo de Partidos en los departamentos 2015 (Elecciones de asambleas departamentales).

\begin{tabular}{ccccccccc} 
Departamentos & NEPE & IC & Departamento & NEPE & IC & Departamentos & NEPE & IC \\
\hline Amazonas & 9.77 & 28,4 & Chocó & 7.01 & 36,9 & Putumayo & 7.70 & 37,1 \\
\hline Antioquia & 6.79 & 34,2 & Córdoba & 4.58 & 48,8 & Quindío & 5.22 & 44,6 \\
\hline Arauca & 5.93 & 45,9 & Cundinamarca & 7.26 & 32 & Risaralda & 5.70 & 37,8 \\
\hline Atlántico & 4.83 & 48,3 & Guainía & 8.82 & 29,8 & San Andrés & 6.92 & 37,2 \\
\hline Bolívar & 6.50 & 36,6 & Guaviare & 7.56 & 36,7 & Santander & 7.98 & 27 \\
\hline Boyacá & 6.27 & 37,8 & Huila & 6.82 & 32,5 & Sucre & 5.37 & 40,2 \\
\hline Caldas & 5.64 & 43 & La Guajira & 6.34 & 37,7 & Tolima & 7.00 & 36,2 \\
\hline Caquetá & 9.11 & 29,9 & Magdalena & 6.55 & 36,7 & Valle del Cauca & 7.44 & 31,8 \\
\hline Casanare & 7.22 & 32,8 & Meta & 6.90 & 34,5 & Vaupés & 5.95 & 44,6 \\
\hline Cauca & 7.77 & 33,8 & Nariño & 6.70 & 35,7 & Vichada & 8.00 & 35,3 \\
\hline Cesar & 7.50 & 35,2 & N. de Santander & 6.45 & 38,7 & & &
\end{tabular}

Fuente: elaboración del autor con base en estadísticas electorales de la Registraduría Nacional del Estado Civil, elecciones locales de 2015.

\section{Partidos desestructurados y lógicas divergentes de asociación}

En estas elecciones se repitieron las coaliciones y alianzas divergentes que, como ya se ha expuesto, se derivan de la débil articulación vertical entre los niveles nacionales y regionales de los partidos. En la mayoría de los partidos, los políticos actúan con gran autonomía sin que existan directrices desde la dirección nacional respecto a cómo coligarse o cómo hacer alianzas. Cada político trata de obtener los mejores resultados, por lo que se presentan todo tipo de asociaciones, y el partido que es aliado en unos departamentos es adversario en otros.
La decisión sobre las alianzas y coaliciones depende de las condiciones específicas de cada departamento. En algunos son el resultado de los acuerdos entre dirigentes de cada partido en donde hay rivalidades intrapartidistas por las disputas de los electorados fragmentados que son el resultado de la capacidad de intermediación y de organización de las facciones de senadores, representantes a la Cámara, concejales, exgobernadores, incluso clanes políticos. En otros departamentos en donde hay solo un congresista o un político regional con mayor poder, es este quien termina decidiendo o influyendo quien será el candidato de su partido o 
el preferido en una coalición o alianza. En otros hay auto postulaciones de personalidades con cierta trayectoria, en algunos casos ex gobernadores o excongresistas, o también políticos que se declaran independientes y deciden postularse a través del respaldo de firmas de grupos significativos de ciudadanos y luego empiezan a gestionar uniones. La dirección central de los partidos no suele negar avales a sus candidatos o a las coaliciones, también les interesa mantener el mayor número de políticos dentro de sus huestes.

En general, impera el pragmatismo en las coaliciones y en las alianzas, aunque muchas se anuncian como coaliciones oalianzas programáticas, en realidad se trata de negociaciones o pactos de mutua conveniencia y por reparto de poder, de cuotas burocráticas, de manejo de sectores de la administración del departamento y los beneficios que se desprenden de ellos, como contratos o acuerdos con otros dirigentes, posicionamiento e influencia política.

De estas dinámicas se excluyen los partidos con más clara orientación ideológica que poco se asocian: el PDA y el Centro Democrático, que, en medio de partidos pragmáticos y clientelares, son los partidos con menor éxito en las elecciones, pues su capacidad de movilización de electores en los departamentos es muy débil: el primero perdió la única gobernación que tenía (Nariño), y el segundo solo obtuvo una gobernación asociado con el MIRA (Casanare) e hizo parte de 1 coalición y 2 alianzas más.

\section{Las elecciones de 2019 La coordinación estratégica diluye a los partidos}

En las elecciones de 2019 siguió aumentando el número de coaliciones exitosas, estas ganaron en 25 de los 32 departamentos (en el 78.1\%), se redujeron sustancialmente las alianzas informales a 4 (12.5\%) y se mantuvieron en 3 los gobernadores elegidos por un solo partido (9.4\%). Configurándose ya un patrón, como en las dos elecciones anteriores las coaliciones son la principal estrategia electoral exitosa en elecciones de gobernadores en el país. En muy pocos casos los partidos compiten de forma individual, solo en 3 departamentos periféricos, poco poblados y en dónde se ganan las elecciones con pocos miles de votos y hay espacio para que un partido logre imponerse solo, este fue el caso de Casanare, Guainía y Vaupés.

Las elecciones tuvieron siete rasgos principales:

(a) Aumentó de forma significativa el número de partidos respecto de las dos elecciones previas. Participaron 12 partidos que tenian presencia nacional y contaban con representación en el Congreso de la República, obtenida en las elecciones de 2018 (los partidos Liberal, Conservador, Cambio Radical, Alianza Verde, Social de Unidad Nacional, Polo Democrático Alternativo, Centro Democrático, MIRA, Opción Ciudadana, Alianza Social Independiente, Autoridades Indígenas de Colombia, MAIS). También compitieron nuevas agrupaciones recientemente creadas: Colombia Justa Libres, creado en 2017 la cual agrupa a organizaciones religiosas evangélicas y tenía representación en el Congreso de la república ${ }^{16}$; el movimiento Alianza Democrática Afrocolombiana (ADA), creado en 2019 con escaño en la Cámara de Representantes ${ }^{17}$; Colombia Renaciente, creado en 2018 a partir de una agrupación de origen afrodescendiente que se convirtió en un frente político plural ${ }^{18}$; Decentes y Colombia Humana, que agrupa desde 2017 a varias organizaciones de izquierda ${ }^{19}$ y el Partido de Reivindicación Étnica (PRE), creado en 2018. ${ }^{20}$ También surgió el Partido Fuerza Alternativa Revolucionaria del Común, producto del proceso de paz entre la guerrilla de las FARC y el Gobierno

\footnotetext{
${ }^{16}$ Este partido surgió de la unión de dos movimientos evangélicos y políticos, Colombia Justa y Libres. El 11 de diciembre de 2017 se inscribió bajo la etiqueta de movimiento significativo de ciudadanos para poder participar en las elecciones de 2018 en las que obtuvo tres senadores y un representante a la Cámara y se convirtió en partido político reconocido legalmente. Este año hizo parte de la coalición ganadora de las elecciones presidenciales en que de 2017; Semana, febrero 20 de 2018)

${ }^{17}$ Esta agrupación fue creada en 2019. Surgió a partir de la curul que ganó en la Cámara el consejo comunitario La Mamuncia, de López de Micay (Cauca) con Hernán Banguero Andrade. Se convirtió en un partido que de forma inusual expidió más de 3.565 avales a candidatos en 26 departamentos, a personas de todos los grupos étnicos y de diversa procedencia también a algunos politicos cuestionados por sus presuntos nexos con organizaciones ilegales. Fueron elegidos 28 concejales en varios municipios del país (El Espectador, agosto 10 de 2019 ; Semana, octubre 12 de 2019 ).

18 Eta agrupación surgió en 2018 cuando el candidato Jhon Arley Murillo Benítez obtuvo una curul por circunscripción especial afrodescendiente en la Ć́mara de Representantes. Renaciente, una comunidad afrocolombiana ubicada en Cali. Pasó a ser un frente amplio de sectores de centro como nuevo partido político. Bajo esta Renaciente, una comunidad afrocolombiana ubicada en Cali. Paso a ser un frente amplio de sectores de centro como nuevo partido político. Bajo esta etiqueta se unieron una serie de políticos veteranos retirados del Partido Liberal Juan Fernando Cristo, Guillermo Rivera, Alfonso Prada, Cla

Gilberto Murillo y Luis Garzon, ex alcalde de Bogota por la agrupacion de izquierda Frente Social y Politico (El Tiempo, marzo 16 de 2019 ).

${ }^{19}$ La Lista de la Decencia, conocida como Decentes, es una coalición política que agrupó a los partidos de centroizquierda e izquierda creada en 2017 y que integró al partido Unión Patriótica, a lo que quedó del viejo Partido Comunista, a la Alianza Social Independiente en algunos departamentos, al grupo Todos somos, Colombia y a la Colombia Humana creado por Gustavo Petro, excandidato presidencial y senador. Obtuvo en 2018 cuatro curules en

${ }^{20}$ El PRE nació de la representación obtenida por el Consejo Comunitario de San Antonio y El Castillo, del municipio El Cerrito (Valle), que reúne a 25 familias afrocolombianas. Después perdió su registro legal al no obtener el mínimo de votos que establece el umbral electoral (El Espectador, enero 15 de 2020$)$.
} 
de Juan Manuel santos (2010-2018). Este partido no participó en las elecciones de gobernadores. En total participaron 17 partidos más los candidatos inscritos por grupos significativos de ciudadanos. A diferencia de la década de 1990 en la que hubo una explosión artificial de partidos que fueron efímeros y que expresaban aventuras electorales, iniciativas personalistas de facciones regionales o múltiples escisiones de los partidos Liberal y Conservador por tensiones y rencillas internas, las nuevas agrupaciones expresan divisiones en la sociedad y la presencia de sectores que buscan espacios de representación y el acceso al poder político regional. Así se expresa en las agrupaciones religiosas cristianas diferenciadas de otras como el MIRA y de la religión mayoritaria católica; también hay organizaciones de negritudes que intentar encauzar a una población étnica minoritaria y sub representada; de igual forma líderes que defienden banderas liberales que se separaron del histórico Partido Liberal por considerar que había perdido su contenido ideológico; lo mismo ocurrió con sectores de izquierda con tendencias diferentes a las dominantes en el PDA, que optaron por escindirse.

(b) De nuevo, los partidos más grandes fueron los que obtuvieron más éxito: Cambio Radical y el Partido Social de Unidad Nacional hicieron parte de 17 coaliciones ganadoras y de una alianza informal; el Partido Liberal participó de 13 coaliciones y 2 alianzas exitosas; el Partido Conservador de 11 coaliciones y 3 alianzas; la Alianza Verde de 5 coaliciones y una alianza; el Centro Democrático participó de 4 coaliciones, 2 alianzas y ganó 2 gobernaciones solo. En algunos departamentos los enfrentamientos centrales se dieron entre grandes coaliciones y esto llevó a que los mismos partidos que triunfaron en la mayoría perdieran en otras.

(c) Los partidos pequeños se integraron también a coaliciones y alianzas ganadoras, aunque en menor proporción. La lógica de la coordinación estratégica se orienta a las uniones entre los grandes $\mathrm{y}$, de forma residual, o en situaciones con alta competitividad, los pequeños adquieren mayor relevancia. Un caso especial es el de ASI. Este partido surgió en 1991 como Alianza Social Indígena, en 2011 decidió convertirse en Alianza Social Independiente, como un partido multicultural. Desde antes había avalado candidatos no indígenas, incluso en elecciones presidenciales.
En estas elecciones avaló candidatos no elegidos en 3 departamentos e hizo parte de 9 coaliciones ganadoras. También hicieron parte de coaliciones AICO, en 2 casos, y avaló candidatos no elegidos en otros 5 departamentos. MAIS hizo parte de 8 coaliciones y una alianza, y avaló a 3 candidatos no elegidos. Colombia Renaciente se incorporó a 7 coaliciones ganadoras y avaló candidatos no elegidos en otros 7 departamentos. Tres partidos no hicieron parte de coaliciones o alianzas ganadores y funcionaron como agencias de expedición de avales: PRE avaló a 4 candidatos y ADA a 8. Ambos, junto con ASI, fueron de nuevo cuestionados por esta expedición indiscriminada de avales, incluso hubo denuncias indicando que cobraban dinero por los avales (El País, agosto 25, 2019).

(d) Como en las elecciones de 2011 y 2015, en estas predominaron las alianzas y coaliciones divergentes: estas dependen de las condiciones específicas en cada departamento, de la proximidad o rivalidad entre los políticos departamentales, de la distribución de las fuerzas electorales o de la presencia de un candidato que logra movilizar apoyos de distinta procedencia. Como se mencionó, esto se explica por el bajo nivel de integración vertical de los partidos y la débil cohesión del centro con la periferia (los departamentos), y la incoherencia en sus actuaciones, en las que predomina el pragmatismo, el clientelismo y los pactos orientados a la distribución de cuotas de poder. Esto se puede observar en la gráfica 3, en la cual se ilustra el entramado de vínculos en las coaliciones y alianzas. En este caso la red de interacciones es mucha más densa debido a la presencia de más partidos y de más coaliciones y alianzas ganadoras. El color verde (alianzas) es menos llamativo que en 2015 porque los partidos optaron por formalizar sus asociaciones temporales. Resaltan también las etiquetas de los grandes partidos y de algunos nuevos que fueron muy activos en sus relaciones como Colombia renaciente y MAIS. Todo lo anterior se observa en la gráfica 3.

(e) A diferencia de las elecciones anteriores, en las que era frecuente que facciones o sectores de un mismo partido en un departamento apoyaran a candidatos diferentes y eran numerosas las alianzas informales, hubo en este año cambios porque se empezaron a aplicar las sanciones a la doble militancia. Esto contribuyó a darle un poco más de cohesión a los partidos, aunque las decisiones sobre 
Gráfico 3. elección de gobernadores de 2019. Trama de coaliciones y alianzas entre partidos

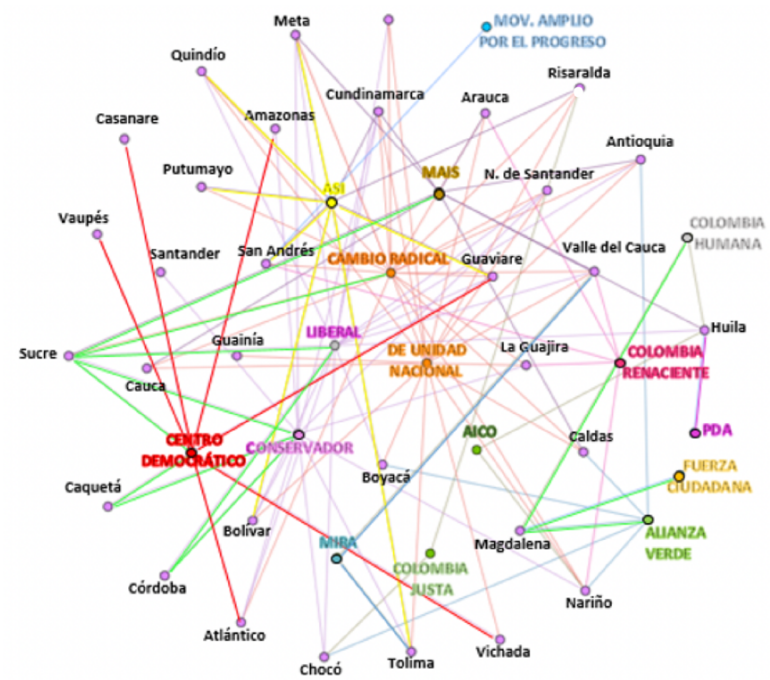

Gobernadores elegidos mediante alianzas. Los demás representan a los gobernadores elegidos mediante coaliciones formales.

Fuente: Elaboración propia con información de la tabla 3

coaliciones y alianzas siguen siendo determinadas, en la mayoría de casos, por los políticos regionales (las excepciones son los partidos religiosos evangélicos, el Centro Democrático y el PDA que han mantenido un control desde sus direcciones nacionales).

(f) De nuevo, los partidos con un perfil más ideológico se incorporaron a menos coaliciones y alianzas, aunque solo la izquierda mantuvo su distancia con la mayoría de partidos. El PDA solo hizo parte de una coalición ganadora (en Huila, con el candidato Luís Enrique Dussán López de la coalición Huila crece con los partidos Liberal, AICO y Colombia Humana) y avaló candidatos no ganadores en 7 departamentos. La agrupación de izquierda Colombia Humana, solo se asoció con el candidato ganador en Magdalena y el movimiento Fuerza Ciudadana. El partido de derecha Centro Democrático se asoció más en estas elecciones e hizo parte de 4 coaliciones ganadoras con un espectro mayor de partidos (en Amazonas con el Partido Conservador, en Atlántico con Cambio Radical, Conservador y Liberal; en Guaviare con Cambio Radical, Liberal y ASI; en Vichada con el Partido Social de Unidad Nacional), participo de 2 alianzas ganadoras (en Caquetá apoyó al candidato del Partido Conservador y en Sucre al candidato del Partido Liberal) y avaló candidatos no elegidos en 7 departamentos. Además, su candidato ganó en 2 departamentos (Casanare y Vaupés). Los partidos religiosos evangélicos ampliaron también su espectro de asociados, Colombia Justa Libres hizo parte de 2 coaliciones (en Chocó, con los partidos Liberal, Alianza Verde y Conservador; en Risaralda con Cambio Radical, Partido Social de Unidad Nacional y ASI) y avaló candidatos no elegidos en 16 departamentos, y el MIRA participó de 2 coaliciones ganadoras (en Tolima con los partidos Social de Unidad Nacional, Conservador y ASI, y en el Valle del Cauca con Cambio Radical, Social de Unidad Nacional, Liberal, MAIS y Colombia Renaciente).

(g) Como en elecciones anteriores, solo en departamentos con muy poca población ubicados en zonas periféricas ganaron candidatos apoyados por un partido, en estos departamentos se eligen mandatarios con pocos miles de votos: en Guainía (9.965), en Vaupés (3.870) y en Casanare, el más grande (87.666).

\section{Más partidos, más fragmentación y menos cohesión interna}

Los tres factores que inciden en este predominio de las coaliciones como estrategia electoral, en las elecciones para gobernadores siguen estando presentes, y en los dos primeros hubo algunos cambios que contribuyeron a incentivarla aún más. Por una parte, sigue vigente la normatividad sobre coaliciones, pero se le adicionó un elemento con la aprobación del Estatuto de la Oposición (Ley 1909 de 2018). Se estableció que los candidatos que sigan en votos al ganador a alcaldías y gobernaciones (también a la Presidencia y Vicepresidencia) tendrían derecho a ocupar una curul en la corporación pública, para el caso en la Asamblea Departamental (Art. 25). Esto incentivo la competencia e hizo que, además de disputar el primer cargo del departamento, hubiera un premio para el segundo, y esto hizo que los candidatos mejor posicionados hicieran más esfuerzo por coordinar coaliciones competitivas, pues aun perdiendo, ganaban una curul y el respectivo posicionamiento, y mayor influencia política, una voz que representaba a los perdedores. No se pierde todo, se gana un cierto espacio con vocería, acceso a medios, derecho a réplica y un lugar para seguir vigentes.

Respecto al segundo factor, la competencia electoral se hizo aún más fuerte. Como se observa en la tabla 6, en todos los departamentos, el NEPE para asambleas departamentales fue superior a 
Tabla 5. Coaliciones y alianzas electorales en elección de gobernadores de 2019.

Departamento
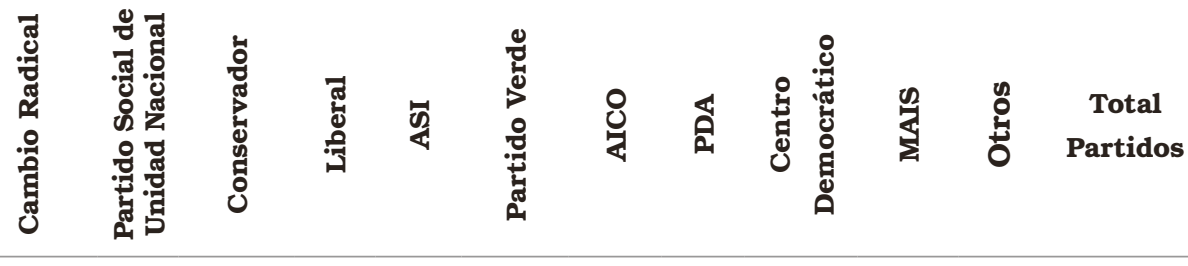

Gobernaciones mediante coaliciones formalizadas

\begin{tabular}{|c|c|c|c|c|c|c|c|c|c|c|c|}
\hline Amazonas & & & 1 & & & & & 1 & & & 2 \\
\hline Antioquia & 1 & 1 & & 1 & & 1 & & & 1 & & 5 \\
\hline Arauca & 1 & 1 & & & & & & & 1 & 1 & 4 \\
\hline Atlántico & 1 & & 1 & 1 & & & & 1 & & & 4 \\
\hline Bolivar & & 1 & 1 & 1 & 1 & & & & & & 4 \\
\hline Boyacá & & 1 & & 1 & & 1 & & & & & 3 \\
\hline Caldas & 1 & 1 & & & & 1 & & & 1 & & 4 \\
\hline Cauca & 1 & 1 & & & & & & & 1 & & 3 \\
\hline Cesar & 1 & 1 & & 1 & & & & & & & 3 \\
\hline Cundinamarca & 1 & 1 & 1 & 1 & 1 & & & & 1 & & 7 \\
\hline Chocó & & & 1 & 1 & & 1 & & & & 1 & 5 \\
\hline Guaviare & 1 & & & 1 & 1 & & & 1 & & & 4 \\
\hline Huila & & & & 1 & & & 1 & 1 & 1 & 1 & 5 \\
\hline La Guajira & 1 & 1 & 1 & & & & & & & 1 & 4 \\
\hline Meta & 1 & 1 & 1 & 1 & 1 & & & & 1 & & 6 \\
\hline Nariño & 1 & 1 & 1 & & & $1^{*}$ & 1 & & & 1 & 6 \\
\hline N. de Santander & 1 & 1 & 1 & 1 & & & & & & & 4 \\
\hline Putumayo & 1 & & & & 1 & & & & & & 2 \\
\hline Quindío & 1 & 1 & & 1 & 1 & & & & & & 4 \\
\hline Risaralda & 1 & 1 & & & 1 & & & & & 1 & 4 \\
\hline San Andrés y P. & 1 & & & & 1 & & & & & 2 & 4 \\
\hline Santander & & & 1 & & & & & & & 1 & 2 \\
\hline Tolima & & 1 & 1 & & 1 & & & & & 1 & 4 \\
\hline Valle del cauca & 1 & 1 & & 1 & & & & & 1 & 2 & 6 \\
\hline Vichada & & 1 & & & & & & 1 & & & 2 \\
\hline \multicolumn{12}{|c|}{ Gobernaciones mediante alianzas electorales informales } \\
\hline Magdalena & & & & & & 1 & & & & 2 & 3 \\
\hline Caquetá & & & 1 & & & & & 1 & & & 2 \\
\hline Casanare & & & & & & & & 1 & & 1 & 2 \\
\hline Córdoba & & & 1 & 1 & & & & & & 1 & 3 \\
\hline Sucre & 1 & & 1 & 1 & & & & 1 & 1 & & 5 \\
\hline \multicolumn{12}{|c|}{ Gobernaciones elegidas por un solo partido } \\
\hline Guainía & & 1 & & & & & & & & & 1 \\
\hline Vaupés & & & & & & & & 1 & & & 1 \\
\hline
\end{tabular}

*Sectores o facciones de los partidos.

Otros: en Arauca, Colombia Renaciente; Cauca, Colombia Renaciente; Casanare, el MIRA; Córdoba, Colombia Humana; Chocó, Colombia Justa Libre; Huila, Colombia Humana; La Guajira, Colombia Renaciente;

Magdalena, Fuerza Ciudadana con la Colombia Humana; Meta, Colombia Renaciente; Nariño, Colombia

Renaciente; Risaralda, Colombia Justa Libres; en San Andrés, Colombia Renaciente y el Movimiento Amplio por el progreso del archipiélago; en Santander, Partido Conservador; en el Tolima, el MIRA; Valle del Cauca, MIRA y Colombia Renaciente.

Fuente: elaboración propia con base en Registraduría Nacional del Estado Civil y las fuentes citadas en cada caso. 
4.40, el mayor fue de 10.56 y el promedio nacional fue de 7.25, asimismo, el IC solo en un departamento superó por poco el $50 \%$, y los valores son inferiores a los de elecciones anteriores, la mayoría inferiores al 40\% (ver tabla 6). En todos los departamentos hay un alto número de partidos y ninguno cuenta con mayorías suficientes para imponerse solo en las elecciones, por esto se requiere de coaliciones formales o alianzas informales para ganar.

Tabla 6. Número Efectivo de Partidos en los departamentos 2019 (Asambleas Departamentales).

\begin{tabular}{ccccccccc} 
Departamentos & NEPE & IC & Departamento & NEPE & IC & Departamentos & NEPE & IC \\
\hline Amazonas & 10.56 & 23,4 & Chocó & 7.84 & 34,8 & Putumayo & 7.70 & 28.8 \\
\hline Antioquia & 6.47 & 33,4 & Córdoba & 4.87 & 44,8 & Quindío & 5.22 & 37.4 \\
\hline Arauca & 7.38 & 39,2 & Cundinamarca & 7.33 & 28,6 & Risaralda & 5.70 & 36.2 \\
\hline Atlántico & 4.75 & 45,8 & Guainía & 9.11 & 30,1 & San Andrés & 6.92 & 37.2 \\
\hline Bolívar & 6.66 & 33,2 & Guaviare & 7.61 & 33,5 & Santander & 7.98 & 21.9 \\
\hline Boyacá & 6.15 & 40,8 & Huila & 6.90 & 34,3 & Sucre & 5.37 & 53.3 \\
\hline Caldas & 5.98 & 39,8 & La Guajira & 4.82 & 47,3 & Tolima & 7.00 & 31.9 \\
\hline Caquetá & 7.47 & 35.0 & Magdalena & 6.34 & 37,6 & Valle del Cauca & 7.44 & 32.3 \\
\hline Casanare & 7.27 & 35,9 & Meta & 8.18 & 27,7 & Vaupés & 5.95 & 33.9 \\
\hline Cauca & 8.82 & 24,2 & Nariño & 7.10 & 32,6 & Vichada & 8.00 & 28.0 \\
\hline Cesar & 8.43 & 30,2 & N. de Santander & 6.91 & 33 & & &
\end{tabular}

Fuente: elaboración del autor con base en estadísticas electorales de la Registraduría Nacional del Estado Civil, elecciones locales de 2019.

En cuanto a los partidos políticos, estos se cohesionaron un poco al empezar a aplicarse las sanciones a la doble militancia, y ello evitó los apoyos divididos de un mismo partido a candidatos diferentes, al menos oficial o públicamente. No obstante, la poca cohesión vertical se siguió expresando con las coaliciones divergentes. Los partidos no son coherentes en sus coaliciones y alianzas, y los partidos adversarios en un departamento son aliados en otro. Con excepción del PDA y la Colombia Humana, y en menor medida en el centro Democrático, los partidos se asocian entre sí casi con todos. De esto se excluyen los partidos ubicados más a la izquierda como el PDA, Colombia Humana, la Unión Patriótica y el nuevo partido Fuerza Alternativa Revolucionaria del Común, que se mantienen distantes de la gran mayoría de fuerzas políticas, especialmente con el Centro Democrático y Colombia Justa Libres.

\section{Sintesis y conclusiones}

Este artículo ha presentado evidencias a favor del encuadre analítico que sostiene que en las coaliciones en las elecciones regionales o territoriales inciden tres condiciones o factores centrales: las reglas de juego (específicamente la regulación que permite las candidaturas multipartidistas o mediante coavales, su financiación y los estímulos a los competidores para que coordinen sus acciones), el nivel de fragmentación del sistema de partidos (que hace poco probable que candidatos unipartidistas ganen las elecciones ante la alta competencia y el alto número de partidos, en sistemas multipartidistas en los que compiten minorías termina imponiéndose la coordinación estratégica entre partidos y facciones) y las características de los partidos (el predominio de partidos pragmáticos con bajo perfil ideológico $\mathrm{y}$ sin diferencias sustanciales facilita las alianzas y coaliciones).

Asimismo, el artículo hace un aporte a este tipo de estudios al proporcionar una amplia información empírica sobre las alianzas y coaliciones en las elecciones para gobernadores en el país. Se resaltan cuatro conclusiones centrales. Por una parte, predomina la coordinación estratégica que se expresa en que en las tres elecciones se imponen las 
coaliciones formales (reglamentadas por las normas) en y las alianzas informales (pactos o acuerdos entre políticos, a veces públicos, a veces más ocultos). Por otra parte, los partidos más grandes tienden a asociarse entre sí y son ganadores a través de coaliciones, los pequeños partidos entran en algunas coaliciones como aliados que ayudan a agregar votos en escenarios muy competitivos. En tercer lugar, imperan las alianzas y coaliciones divergentes: los partidos no son consistentes en sus asociaciones, los partidos que en un departamento son rivales, en otros son aliados. Esto es el resultado de la débil articulación vertical de los partidos. En cuarto lugar, los partidos con un mayor perfil ideológico establecen menos alianzas y coaliciones, cuando lo hacen, es con partidos que consideran muy cercanos en sus orientaciones y contenidos programáticos. Este es el caso de los partidos de izquierda: PDA, Colombia Humana, la Unión Patriótica; y de los partidos identificados como de derecha, el CD, el MIRA y Colombia Justa Libres. Aunque en 2019 el CD relajó sus posiciones y se asoció con partidos con los cuales a nivel nacional había tenido debates y contradicciones.

La presencia mayoritaria de alianzas y coaliciones entre partidos predominantemente pragmáticos, sin integración vertical y divergentes, es problemática para para la democracia en los departamentos en varios sentidos. Respecto a los balances sobre el tamaño, la fuerza e importancia de los partidos: ante la lógica asociativa casi indiscriminada entre los partidos y los gobiernos compartidos o en condominio. ¿A quién se le computan los votos? ¿Qué partidos son ganadores y cuáles son perdedores? Además de los tradicionales indicadores de número de votos, número de curules en Concejos y Asambleas, hay que considerar el número de coaliciones y alianzas de las que hizo parte cada partido. Esto conlleva el problema de la doble computación, pues se le terminan atribuyendo éxitos a todos y, finalmente, parece que nadie o muy pocos pierden. Todos se declaran vencedores.

Otra cuestión importante se refiere al poder del ciudadano y del elector en las elecciones: ¿eligen los electores o eligen los aliados? Un candidato fuerte no parece ser aquel que movilice más votos, o el que tenga mayor ascendencia sobre la población con base en propuestas, su acción política, sus antecedentes y su trayectoria, sino el que logre agregar más electores procedentes de partidos, movimientos y facciones que logre articular y que tienen sus propias redes departamentales y locales de clientelas. Con algunas excepciones notables de candidatos apoyados por organizaciones sociales y electores no incorporados a estas redes, la mayoría de los gobernadores son el resultado de la capacidad de pactar, de negociar y de agregar clientelas electorales que son movilizadas por los respectivos jefes partidistas o faccionales.

En cuanto a la representación, surge también un gran interrogante. Dado que los gobernadores ganadores son mayoritariamente candidatos de coaliciones multiformes de diversa procedencia y en muchos casos con un alto número de partidos y facciones incorporadas ¿a quién representan los mandatarios? ¿Responden a los intereses colectivos y gobernarán para todos o para sus asociados políticos? Dada la tradición clientelar de la política colombiana, los altos niveles de corrupción política y administrativa y la opacidad de la financiación de las campañas, hay una alta probabilidad de que la gestión pública departamental se rija por la distribución de cuotas de poder a todos los que han aportado a la elección, que la contratación, la elección de funcionarios, la inversión pública obedezca más a intereses particulares y de grupos que al interés colectivo. ${ }^{21}$

Finalmente, en cuanto a la accountability, ¿a quién se le pide cuentas de la gestión? Como no hay reelección inmediata no hay posibilidades de premiar o castigar al gobernante y tampoco hay claridad de a quién pedirle rendición de cuentas ante tantos socios incorporados a las coaliciones y alianzas. Se diluye la responsabilidad, aunque para efectos administrativos y penales es el gobernador quien termina responsabilizándose de las acciones de gobiernos que comparte con otros.

\section{Bibliografia:}

Albarracín, J., \& Milanese, J. (4 de noviembre de 2019). En Colombia se refirma la desinstitucionalización del sistema de partidos. Agenda pública El País. Recuperado de: http://agendapublica.elpais.com/encolombia-se-reafirma-la-desinstitucionalizacion-del-sistemade-partidos/ 
Amyle, D. (1987). The federal condition in Canada. Mc GrawHill Ryerson.

Áreacucuta.com (octubre 30 de 2011). Edgar Díaz Nuevo gobernador electo Norte de Santander. Recuperado de: https://www.areacucuta.com/edgardiaz-nuevo-gobernador-electo-de-norte-de-santander/

Basset, Y., \& Franco, L. (2020). Coaliciones y movimientos por firmas: la danza de los logos. En Barrero, F., \& Richard, E. Elecciones subnaciones 2019. Una redefinición de los partidos y de sus campañas electorales. (87-117) Bogotá: Konrad Adenauer Stiftung.

Batle, M., \& Puyana, J. (2015). Cuando todo queda entre amigos: coaliciones y consolidación de nuevas fuerzas electorales en Santander y Norte de Santander. En Barrero, F. (Ed.), Elecciones regionales 2015: los retos de un país en camino hacia la paz. (119 - 156), Bogotá: Konrad Adenauer Stiftung.

Botero, F., \& Alvira, D. (2012). Fulano de tal va por su aval. Desconexión entre los niveles nacionales y locales de los partidos políticos en Colombia, en Política y territorio. En Wills, L., \& Batlle, M. (Comp), Análisis de las elecciones subnacionales en Colombia, 2011 (131-161). Bogotá: PNUDIDEA.

Calderón, J. (2019). Colombia: el mapa cambió tras las regionales, Celag.org, recuperado de: https://www. celag.org/colombia-el-mapa-cambio-tras-las-regionales/

Clerici, P. y Gerardo S. (2014). La regulación de las alianzas electorales y sus consecuencias en sistemas políticos multi-nivel en América Latina. Revista Electrónica del Instituto de Investigaciones "Ambrosio L. Gioja" (12)77-98. Recuperado de: http://www.derecho.uba.ar/revistas-digitales/index.php/ revista-electronica-gioja/article/view/77/58

Clerici, P. (2015). La creciente importancia de las alianzas electorales en un escenario de competencia territorializada. El caso argentino. Revista SAAP, 9(2), 313-41. Recuperado de: http://www.redalyc.org/ articulo.oa?id=387143598004

Cox, G. (1997). Making Votes Count. Strategic Coodination in the Worlds Electoral Systems. Nueva York: Cambridge University Press. https://doi.org/10.1017/ CBO9781139174954

Dávila, A. (2020). Desarticulaciones partidistas: diálogos entre el partido nacional y el partido en las regiones. En Barrero, F., \& Richard, E. Elecciones subnaciones 2019. Una redefinición de los partidos y de sus campañas electorales. Konrad Adenauer Stiftung: Bogotá

Duque, J. (2014). Gobernadores y corrupción en la Costa Atlántica. Clanes políticos, políticos de negocios y paramilitarismo, Ciudad PazAndo, 7 (2), p.174200 https://doi.org/10.14483/udistrital.jour.cpaz.2014.2.a10
Duque, J. (2015). Corrupción, organizaciones criminales y accountabiity, Programa Editorial Universidad del Valle, Colombia.

Duque, J. (agosto 3, 2020). El Cesar: devastado por sus gobernadores. Razón Pública. Recuperado de: https://razonpublica.com/cesar-devastado-gobernadores/

El Colombiano (junio 6 de 2015). Soy un candidato de opinión: Luís Pérez G. Recuperado de: https:// www.elcolombiano.com/antioquia/yo-soy-un-candidatode-opinion-luis-perez-g-MX2088835

El Espectador (julio 17 de 2015). Los enredos de un candidato a la gobernación en Guaviare. Recuperado de: https://www.elespectador.com/noticias/politica/losenredos-de-un-candidato-a-la-gobernacion-del-guaviare/

El Espectador (octubre 20 de 2015). Alianza Verde pisa fuerte en Nariño. Recuperado de: https://www.elespectador. com/noticias/politica/alianza-verde-pisa-fuerte-en-narino/

El Espectador (octubre 28 de 2017). Colombia Justa Libres: la apuesta electoral cristiana. Recuperado de: https://www.elespectador.com/noticias/politica/colombiajusta-libres-la-apuesta-electoral-cristiana/

El Espectador (julio 31 de 2019). Fisuras en Alianza Verde por coaval a Anibal Gaviria en Antioquia. Recuperado de: https:/www.elespectador.com/noticias/ politica/fisuras-en-la-alianza-verde-por-coaval-a-anibalgaviria-en-antioquia/

El Espectador (septiembre 24 de 2019). Uribismo le quitó apoyo a Vicente Blel. Recuperado de: https:// www.elespectador.com/noticias/alto-turmeque/uribismole-quito-apoyo-vicente-blel-en-campana-pero-se-declaropartido-de-gobierno-en-bolivar-articulo-906192/

El Espectador (octubre 27 de 2019). Con una estrecha ventaja, el Centro Democrático repite en la gobernación de Casanare. Recuperado de: https://www.elespectador.com/noticias/nacional/conuna-estrecha-ventaja-el-centro-democratico-repite-en-lagobernacion-de-casanare/

El Espectador (octubre 27 de 2019). Everth Hawkins es el nuevo gobernador de San Andrés. Recuperado de: https://www.elespectador.com/noticias/nacional/ everth-hawkins-es-el-nuevo-gobernador-de-san-andres/

El Espectador (octubre 19 de 2019). Facundo Castillo es el gobernador electo de Arauca. Recuperado de: https://www.elespectador.com/noticias/nacional/facundocastillo-es-el-gobernador-electo-de-arauca/ El Espectador (agosto 10 de 2019). ADA, el partido afro de los más de 35000 avales. Recuperado de: https://www. elespectador.com/noticias/politica/ada-el-partido-afro-de-losmas-de-3500-avales/

El Espectador (enero 15 de 2020). Consejo de Estado niega demanda que buscaba revivir personería jurídica del PRE. Recuperado de: https://www. elespectador.com/noticias/politica/consejo-de-estadoniega-demanda-que-buscaba-revivir-personeria-juridicadel-pre-articulo-899998/ 
El Heraldo (septiembre 9 de 2015). Definidos los conservadores, así quedan los apoyos a la gobernación. Recuperado de: https://www.elheraldo. co/politica/asi-esta-la-baraja-de-congresistas-ocho-apoyanverano-y-siete-varela-216273

El País (agosto 25 de 2019). Los tres partidos novatos que se volvieron fábricas de avales. Recuperado de: https://www.elpais.com.co/contenido-premium/los-trespartidos-novatos-que-se-volvieron-fabricas-de-avales-paraelecciones.html

E1 Nuevo Siglo (septiembre 4 de 2011). Ha sido positivo el ejercicio de ser candidato por firmas. Recuperado de: https://www.elnuevosiglo.com.co/articulos/9-2011ha-sido-positivo-el-ejercicio-de-ser-candidato-por-firmasalan-jara

El Nuevo Siglo (septiembre 16 de 2011). Departamento de Nariño está en total abandono: Chamorro. Recuperado de: https://www.elnuevosiglo.com.co/ articulos/9-2011-departamento-de-narino-esta-en-totalabandono-chamorro

El Nuevo Siglo (octubre 15 de 2019). CR podría dar golpe de gracia en el Meta. Recuperado de: https://www. elnuevosiglo.com.co/articulos/10-2019-cr-podria-dargolpe-de-gracia-electoral-en-meta

El Nuevo Siglo (octubre 21 de 2019). En Guainía la U le hace frente a dos coaliciones para Gobernación. Recuperado de: https://www.elnuevosiglo.com.co/ articulos/10-2019-en-guainia-la-u-le-hace-frente-doscoaliciones-para-gobernacion

El Tiempo (octubre 27 de 2011). Partidos tradicionales, en franca lid por Tolima. Recuperado de: https://www. eltiempo.com/archivo/documento/MAM-4923734

El Tiempo (enero 7 de 2012). Luis Miguel Cotes, el cuestionado acordeonero que gobierna Magdalena. Recuperado de: https://www.eltiempo.com/archivo/documento/CMS10939769

El Tiempo (octubre 5 de 2015). Luís Pérez candidato a la gobernación de Antioquia por la Unidad Nacional. Recuperado de: https://www.eltiempo.com/ archivo/documento/CMS-16395541

El Tiempo (octubre 28 de 2019). Héctor Olimpo, el hombre que ganó en las urnas al polémico Yahir Acuña. Recuperado de: https://www.eltiempo.com/colombia/ otras-ciudades/hector-olimpo-gano-en-las-urnas-apolemico-yahir-acuna- 428048

El Tiempo (octubre 28 de 2019). Histórico: Cauca eligió a su primer gobernador afrodescendiente. Recuperado de: https://www.eltiempo.com/colombia/ otras-ciudades/elias-larrahondo-carabali-gano-comoprimer-gobernador-afrodescendiente-del-cauca- 428222

Fernández de Mantilla, L. (2011). Elecciones 2011 en Santander y Bucaramanga: alianzas y candidaturas. OPERA. 11(11), 87-104.

Fiscalía General de la Nación. (Julio 16, 2020). Recuperado de: https://www.fiscalia.gov.co/colombia/bolsillos- de-cristal/sentido-de-fallo-condenatorio-contra-elgobernador-de-cesar).

Fleischer, D. (2007). A política de coligações no Brasil Antes e depois da verticalização (1994 E 1998 vs. 2002 E 2006): Impactos sobre os partidos. Série CEPPAC (6) 1-22. Recuperado de: http:// www.coalicionesgicp.com.ar/wp-content/uploads/2016/02/ Fleischer2007.pdf

Florencianos.com (agosto 5 de 2019). Más personas se suman a la campaña de César Torres Ríos. Recuperado de: https://www.florencianos.com/maspersonas

Gamson, W. (1961). A Theory of Coalition Formation. American Sociological Review, 26(3), 373-382. https://doi.org/10.2307/2090664

García, M. (El Tiempo, octubre 12 de 2019). Candidatos por coaliciones y firmas desdibujan a los partidos. Recuperado de: https://www.eltiempo.com/ elecciones-colombia-2019/elecciones-2019-candidatos-porcoaliciones-y-firmas-desdibujan-a-los-partidos-422648

Garay, L., \& Salcedo, E. (2010). Crimen, captura y reconfiguración cooptada del Estado: cuando la descentralización no contribuye a profundizar la democracia. En Ospina, J. (ed), 25 años de la descentralización en Colombia. pp. 89-138. Bogotá: Konrad Adenauer Stiftung.

Golder, S. (2006). Pre-electoral Coalition Formation in Parliamentary Democracies, British Journal of Political Science, 36(2), 193-212.

Gómez, T. \& Ramírez, E. (2012). La ficción del Estado Nación. Configuración territorial del Estado en el departamento del Caquetá, Universidad de Antioquia. Medellín. Colección Mejores trabajos de grado.

Hernández, A.(2013). Colombia: entre los partidos y las coaliciones. En: memorias del II Congreso Iberoamericano de Derecho Electoral, Bogotá.

Hoyos, M. (2007). La reforma política de 2003 y su impacto sobre el sistema de partidos. En Entre la persistencia y el cambio. Reconfiguración del escenario partidista y electoral en Colombia, comp. Hoyos, M. 174-215. Bogotá, Universidad del Rosario.

Konrad, A. (2017). KasPaper No. 31. La presentación de listas en coalición a corporaciones públicas. Elementos para su regulación en Colombia. Pontificia Universidad javeriana y Misión de Observación Electoral.

Laakso, M., \& Rein, T. (1979). The "Effective" Number of Parties. A Measure with Application to West Europe. Comparative Political Studies, 12 (1), 3-28. https://doi.org/10.1177/001041407901200101

Las2orillas.com (septiembre 24 de 2019). Casanare: que entre el diablo y escoja. Recuperado de: https:// www.las2orillas.co/casanare-que-entre-el-diablo-y-escoja/ 
lasillavacia.com (11 de mayo de 2011). El MIO la reencarnación de ADN de Juan Carlos Martínez. Recuperado de: https://lasillavacia.com/historia/el-miola-reencarnacion-del-adn-de-juan-carlos-martinez-24242

Lasillavacia.com (agosto 1 de 2011). El Partido Liberal cambia los votos del "Mello" Cotes por la imagen de Carlos Caicedo en el Magdalena. Recuperado de: https://lasillavacia.com/historia/el-partido-liberalcambia-los-votos-del-mello-cotes-por-la-imagen-de-carloscaicedo-en-el-m

Lasillavacia.com (agosto 3 de 2011). El acuerdo político del Cesar: ¿pacto político o guerra sucia? Recuperado de: https://lasillavacia.com/historia/ el-acuerdo-politico-del-cesar-pacto-politico-o-guerrasucia-26337

Lasillavacia.com (agosto 17 de 2011). Héctor Fabio Useche, el candidato 'powered by' Juan Carlos Martínez y Juan Carlos Abadía. Recuperado de: https:// lasillavacia.com/historia/hector-fabio-useche-el-candidatopowered-juan-carlos-martinez-y-juan-carlos-abadia-26754

Lasillavacia.com (octubre 4 de 2011). ASI, Afrovides y AICO, fábrica de avales. Recuperado de: https://lasillavacia. com/historia/asi-afrovides-y-aico-fabricas-de-avales-28163

Lasillavacia.com (julio 13 de 2016). José Antonio Segebre. Recuperado de: https:/lasillavacia.com/quienesquien/ perfilquien/jose-antonio-segebre-berardinelli

Lasillavacia.com (agosto 12 de 2016). Dumek Turbay Paz. Recuperado de: https://lasillavacia.com/quienesquien/ perfilquien/dumek-turbay-paz

Lasillavacia.com (agosto 3 de 2017). Carlos Julio González Villa. Recuperado de: https:/lasillavacia.com/ quienesquien/perfilquien/carlos-julio-gonzalez-villa

Lasillavacia.com (agosto 19 de 2017). El entramado político en el lío de la hemofilia en Bolívar. Recuperado de: https:/lasillavacia.com/silla-caribe/el-entramadopolitico-en-el-lio-de-la-hemofilia-en-bolivar-62214

Lasillavacia.com (diciembre 7 de 2017). Guido Echeverri Piedrahita. Recuperado de: https://lasillavacia.com/ quienesquien/perfilquien/guido-echeverri-piedrahita

Lasillavacia.com (febrero 3 de 2018). Edgar Enrique Martínez Romero. Recuperado de: https://lasillavacia.com/ quienesquien/perfilquien/edgar-enrique-martinez-romero

Lasillavacia.com (febrero 12 de 2019). Sergio Fajardo. Recuperado de: https://lasillavacia.com/quienesquien/ perfilquien/sergio-fajardo

Lasillavacia.com (octubre 27 de 2019). Nicolás García Bustos. Recuperado de: https://lasillavacia.com/ quienesquien/perfilquien/nicolas-garcia-bustos

Lasillavacia.com (octubre 27 de 2019). Victor Manuel Tamayo. Recuperado de: https://lasillavacia.com/ quienesquien/perfilquien/victor-manuel-tamayo

Lasillavacia.com (octubre 31 de 2019). Jhon Rojas, el gobernador funcional de Nariño. Recuperado de: https://lasillavacia.com/silla-pacifico/jhon-rojasgobernador-funcional-narino-74332
Lasillavacia.com (noviembre 17 de 2019). Orlando Benítez. Recuperado de: https:/lasillavacia.com/quienesquien/ perfilquien/orlando-benitez

Méndez de Hoyos, I. (2012). Coaliciones preelectorales y competencia partidista en México a nivel federal y local (1994-2011). Politica y Gobierno. 19(2). 147-98. Recuperado de: http://www.scielo.org.mx/ pdf/pyg/v19n2/v19n2a1.pdf

Milanese, J. (2015). Elecciones de 2015 en la región Pacífico: análisis sistémico de los resultados en el corazón del posconflicto. En Barreo, F. (Ed). Elecciones regionales 2015: los retos de un país en camino hacia la paz. (183-201). Konrad Adenauer Stiftung Bogotá.

Méndez, M. (2004). Federalismo y partidos políticos: los casos de Canadá y España, Workin paper No. 232, Institut de Ciències Polítiques i Socials, Universidad de Murcia.

Mora, L. (2005). Parties as programmatic agents. A test of institutional theory in Brazil. Party Politics, 11(2), 193-216. https://doi.org/10.1177/1354068805049776

Movimiento de Renovación Absoluta (2015). Elecciones 2015: ¡MIRA aumenta su participación en municipios y departamentos! Recuperado de: https://partidomira.com/elecciones-2015

Negrete, V. (2011). Antecedentes y candidaturas actuales en Córdoba, Caja de herramientas. Recuperado de: http://viva.org.co/cajavirtual/svc0270/articulo03.html

Novoa, A. (septiembre 19 de 2011). Los partidos y los avales: más preguntas que respuestas. Razón Pública, Recuperado de: https://razonpublica.com/los-partidosy-los-avales-mas-preguntas-que-respuestas/

Ordeshook, P. (1986). Game theory and political theory: An introduction. New York: Cambridge University Press. https://doi.org/10.1017/CBO9780511666742

Periodicovirtual.com (domingo, 30 de octubre de 2011). Temístocles Ortega Narváez, es el nuevo gobernador del Cauca. Recuperado de: http:// periodicovirtual.com/noticias/17-cauca-popayanvertical/2694-temistocles-ortega-narvaez-es-el-nuevogobernador-del-cauca.html

Proclama. Cauca y Valle (julio 31 de 2019). "Victor Libardo: el cambio viene, es ahora o nunca”. Recuperado de: https://www.proclamadelcauca.com/victor-libardo.

Procuraduría General de la nación (julio 14 de 2014) Procuraduría General de la Nación, en fallo de segunda instancia, confirmó destitución e inhabilidad por 11 años al gobernador de Caquetá y a dos de sus secretarios de despacho por 12 años, Boletín No. 476.

Reniu, J. (2001). Las teorías de las coaliciones políticas revisadas: la formación de gobiernos minoritarios en España, 1977-1996. Disponible en: http:// diposit.ub.edu/dspace/ handle/2445/41541. 
Losada, R., \& Liendo, N. (2016). El partido Centro Democrático en Colombia: razones de su surgimiento y su éxito, Análisis Político, 29(87) 41-59. https://doi.org/10.15446/anpol.v29n87.60717

Semana (agosto 30 de 2011). Afrovides, MIO y PIN: residuos y alianzas sospechosas.

Semana (septiembre 3 de 2013). ¿Quién manda realmente en Sucre?

Semana (marzo 11 de 2017). Oneida Pinto, la caída de la princesa wayúu.

Semana (febrero 5 de 2018). Las diez reglas a las que se comprometieron los de la lista de la decencia.

Semana (febrero 20 de 2018). Los cristianos se cansaron de entregar sus votos a los políticos.

Semana (abril 12 de 2019). La historia de Opción Ciudadana, el partido que Abuchaibe quiere reencauchar.

Semana (octubre 12 de 2019). Las sombras del controvertido ADA.

Semana (octubre 27 de 2019). Efecto teflón en Bolívar: ganó Vicente Blel Scaff.

Semana (octubre 27 de 2019). Elsa Noguera conquista la gobernación de Atlántico.

Semana (octubre 30 de 2019). ¿Con cuantas alcaldías y gobernaciones se quedó cada partido?

Semana (agosto 14 de 2020). El gobernador del miedo: el portazo de la JEP a Kiko Gómez.

Sinergiainformativa.com (junio 11 de 2020). Es el momento de Antioquia para designación de gobernador encargado. Recuperado de: https:// www.sinergiainformativa.com.co/es-el-momento-deantioquia-presenta-terna-para-designacion-de-gobernadorencargado-de-antioquia/

Strom, K. (2013). Una teoría sobre el comportamiento de los partidos políticos competitivos. Andamios, Revista de Investigación Social, (10)23, 119-170. https://doi.org/10.29092/uacm.v10i23.252

Uribe, P. (2016). La elección popular de gobernador en el valle del Cauca: una mirada práctica de su historia. Tesis de maestría en Gobierno, Cali, ICESI.

Vanguardia (octubre 25 de 2015). Didier Tavera gobernador, Leónidas Gómez la sorpresa. Recuperado de: https://www.vanguardia.com/politica/elecciones/ didier-tavera-gobernador-leonidas-gomez-la-sorpresaPBVL333396

Vanguardia (octubre 28 de 2019). Cuatro años después el clan Aguilar retoma el poder en la Gobernación de Santander con Mauricio Aguilar. Recuperado de: https://www.vanguardia.com/politica/el-clan-aguilarretoma-el-poder-en-la-gobernacion-de-santander$\underline{\mathrm{KD} 1603419}$

Wradio.com (marzo 9 de 2018). El monumento de la corrupción en Vichada. Recuperado de: https:// www.wradio.com.co/noticias/actualidad/el-monumentode-la-corrupcion-en-vichada/20180903/nota/3794212.aspx 